Article

\title{
Transcriptome Analysis of Arbuscular Mycorrhizal Casuarina glauca in Damage Mitigation of Roots on $\mathrm{NaCl}$ Stress
}

\author{
Yihan Wang ${ }^{1,+}$, Fengxin Dong ${ }^{1,+} \mathbb{D}$ and Ming Tang ${ }^{1,2, *}$ \\ 1 College of Forestry, Northwest A\&F University, Xianyang 712100, China; 2018060256@nwafu.edu.cn (Y.W.); \\ 2018060258@nwsuaf.edu.cn (F.D.) \\ 2 Guangdong Laboratory for Lingnan Modern Agriculture, State Key Laboratory of Conservation and \\ Utilization of Subtropical Agro-Bioresources, College of Forestry and Landscape Architecture, South China \\ Agricultural University, Guangzhou 510642, China \\ * Correspondence: tangmingyl@163.com; Tel.: +86-1370-922-9152 \\ + These authors contributed equally to this work.
}

check for updates

Citation: Wang, Y.; Dong, F.; Tang, M. Transcriptome Analysis of Arbuscular Mycorrhizal Casuarina glauca in Damage Mitigation of Roots on $\mathrm{NaCl}$ Stress. Microorganisms 2022, 10, 15. https://doi.org/10.3390/ microorganisms 10010015

Academic Editor: Naeem Khan

Received: 16 November 2021

Accepted: 21 December 2021

Published: 23 December 2021

Publisher's Note: MDPI stays neutral with regard to jurisdictional claims in published maps and institutional affiliations.

Copyright: (C) 2021 by the authors. Licensee MDPI, Basel, Switzerland. This article is an open access article distributed under the terms and conditions of the Creative Commons Attribution (CC BY) license (https:// creativecommons.org/licenses/by/ $4.0 /)$.

\begin{abstract}
Casuarina glauca grows in coastal areas suffering long-term damage due to high salt stress. Arbuscular mycorrhizal fungi (AMF) can colonize their roots to alleviate the effects of salt stress. However, the specific molecular mechanism still needs to be further explored. Our physiological and biochemical analysis showed that Rhizophagus irregularis inoculation played an important role in promoting plant growth, regulating ion balance, and changing the activity of antioxidant enzymes. Transcriptome analysis of roots revealed that 1827 differentially expressed genes (DEGs) were affected by both $\mathrm{R}$. irregularis inoculation and $\mathrm{NaCl}$ stress. The enrichment of $\mathrm{GO}$ (Gene Ontology) and KEGG (Kyoto Encyclopedia of Genes and Genomes) showed that most of these DEGs were significantly enriched in ion transport, antioxidant enzyme activity, carbohydrate metabolism, and cell wall. HAK5, KAT3, SKOR, PIP1-2, PER64, CPER, GLP10, MYB46, NAC43, WRKY1, and WRKY19 were speculated to play the important roles in the salt tolerance of $C$. glauca induced by $R$. irregularis. Our research systematically revealed the effect of $R$. irregularis on the gene expression of $C$. glauca roots under salt stress, laying a theoretical foundation for the future use of AMF to enhance plant tolerance to salt stress.
\end{abstract}

Keywords: arbuscular mycorrhizal fungi; Casuarina glauca; transcriptome analysis; salt stress

\section{Introduction}

Soil salinization is one of the main abiotic stresses that endanger plant growth [1]. At present, more than $20 \%$ of irrigated land in the world is facing the impact of soil salinization [2]. $\mathrm{NaCl}$ stress is mainly due to the accumulation of a large amount of $\mathrm{Na}^{+}$ and $\mathrm{Cl}^{-}$in the rhizosphere of plants, which hinders the absorption of water and other mineral ions by the plant roots, thereby inhibiting the growth of plants [3-5]. It even causes dehydration and the death of plants at high concentrations [6,7]. To adapt to soil salinization and maintain growth, plants have evolved a series of strategies, including increasing antioxidant enzyme activity, removing excess reactive oxygen species (ROS) [8], selectively absorbing other ions to maintain the osmotic potential [6], and producing signal substances by changing the level of the hormone [9]. However, plants cannot fully cope the soil salinization only by themselves.

Roots tend to establish a symbiotic relationship with many microorganisms in the soil to deal with the negative effects of salt stress [10]. Arbuscular mycorrhizal fungi (AMF) are obligate symbiotic fungi that can establish a symbiotic relationship with more than $80 \%$ of the plants on the land [11]. By establishing a symbiotic relationship with AMF, plants absorb a larger range of water and minerals to meet their growth needs [12], providing organic matter for AMF to maintain the symbiotic relationship with them [13]. At present, studies have shown that AMF can alleviate the negative effects of salt stress to promote plant growth $[12,14,15]$. The increase in plant salt tolerance caused by AMF is attributed 
to the more effective absorption of water and nutrients [16], better osmotic state [17], protection of enzyme activity [11], increased photosynthesis [18], and alleviation of ion imbalance [19]. Exploring their molecular mechanism is an important step in understanding the salt tolerance induced by AMF. However, such research is limited.

Casuarina glauca can tolerate a high concentration of salt while maintaining its growth [20]. AMF can establish a symbiotic relationship to alleviate the negative effects of salt stress on C. glauca [21]. At present, studies have shown that inoculating Casuarina spp. seedlings with AMF can significantly increase the biomass [22], the ratio of other ions to $\mathrm{Na}^{+}$[23], water absorption, and antioxidant enzyme activity [22,24]. However, the specific molecular mechanism is unclear. RNA sequencing (RNA-seq) is an effective method for studying the transcriptome, which is helpful to explore the molecular mechanism of stress tolerance $[25,26]$. This kind of research has been carried out in several salt-tolerant plant species, such as Spartina alterniflora [27], Populus euphratica [28], and Beta vulgaris [25].

Roots, colonized by AMF, are the first part to be stressed during salt stress. Hence, this article focused on the effects of $\mathrm{NaCl}$ stress and Rhizophagus irregularis on roots. We used RNA-seq to identify the transcriptome profile of $C$. glauca roots under different conditions, revealing the molecular mechanism of $\mathrm{R}$. irregularis mediated $\mathrm{NaCl}$ tolerance. Through the transcriptome analysis, the research attempted to determine the key $\mathrm{NaCl}$ stress response pathways and genes mediated by $R$. irregularis. These results contributed to understanding the mechanism of salt tolerance induced by $R$. irregularis, laying the foundation for further improving the salt tolerance of plants.

\section{Materials and Method}

\subsection{Plant Material}

Seeds of $C$. glauca were provided by the Research Institute of Tropical Forestry, Chinese Academy of Forestry (Guangzhou, China). After surface sterilization in $75 \%$ ethanol solution for $30 \mathrm{~s}$ and $5 \% \mathrm{NaClO}$ solution for $10 \mathrm{~min}$, washing three times with sterile water, and being placed on a sterile filter paper to absorb the water, seeds were placed on the woody plant medium (WPM) to germinate into seedlings, then cultured for 2 months. A best-growing seedling was selected to prepare clonal plants. The leaves of that were divided into several $2 \mathrm{~cm}$ sections, and placed on WPM differentiation medium to differentiate into buds (containing $1.5 \mathrm{mg} \cdot \mathrm{L}^{-1}$ 6-benzyl amino purine, 6-BA; $0.5 \mathrm{mg} \cdot \mathrm{L}^{-1}$ indole acetic acid, IAA). The buds were cut off and inserted in WPM rooting medium (containing $1 \mathrm{mg} \cdot \mathrm{L}^{-1}$ IAA) for rooting. Cultivation conditions: $16 \mathrm{~h}$ light daily, light intensity 3000 lux.

\subsection{Experimental Design}

The experiment was conducted in a completely randomized design with a factorial combination of $2 \times 2$ (salt stress, AMF inoculum) with 3 replicates. There were two levels of salt stress ( 0 and $600 \mathrm{mM} \mathrm{NaCl}$, the screening criteria were shown in Figure S1) and two AMF treatments (NM: no AMF inoculum; AM: inoculation with $R$. irregularis). For each treatment, twelve plants were combined into one replicate.

\subsection{Mycorrhizal Inoculum}

The R. irregularis (BGC BJ09) was obtained from the Beijing Academy of Agriculture and Forestry Sciences (Beijing, China) and multiplied by Lycopersicon esculentum Mill. in sterilized sand. The inoculum contained spores (approximately 44 spores per gram), hyphae, and colonized root pieces. Each AM treatment was treated with $40 \mathrm{~g}$ inoculum. Each NM treatment received the same amount of autoclaved inoculum.

\subsection{Growth Medium}

The soil ( $<2 \mathrm{~mm})$ used in this study was collected at $0-20 \mathrm{~cm}$ depth from soil at Northwest A\&F University. Sand $(<2 \mathrm{~mm})$ was also collected and washed until there was no soil in it. The soil and sand were sterilized after being mixed at a volume ratio of 1:2. The sterilized soil/sand mixture had a pH of $7.6(1: 5$, soil:water, $w / v)$ and contained $34.9 \mathrm{mg} \cdot \mathrm{kg}^{-1}$ avail- 
able nitrogen, $15.8 \mathrm{mg} \cdot \mathrm{kg}^{-1}$ available phosphorous, $165.7 \mathrm{mg} \cdot \mathrm{kg}^{-1}$ available potassium, $17.5 \mathrm{~g} \cdot \mathrm{kg}^{-1}$ organic matter, $132.2 \mathrm{mg} \cdot \mathrm{kg}^{-1}$ soluble sodium, and $37.2 \mathrm{mg} \cdot \mathrm{kg}^{-1}$ chloride.

\subsection{Growth Conditions}

Pots were each filled with $1 \mathrm{~kg}$ of sterilized soil/sand mixture. Inoculation with $R$. irregularis was performed when the clonal plants were transplanted into the pots. After 8 weeks, colonization was identified. The maximum water capacity of the sand and soil mixture $(1 \mathrm{~kg})$ was $250 \mathrm{~mL}$. The content of $600 \mathrm{mM} \mathrm{NaCl}$ was $8.766 \mathrm{~g}$. During the $\mathrm{NaCl}$ stress, $8.766 \mathrm{~g} \mathrm{NaCl}$ was applied 6 times (1.461 $\mathrm{g}$ was applied every three days). The plants were harvested after another 4 weeks. The water capacity was maintained at maximum water capacity by weight every day. Each pot was irrigated with $50 \mathrm{~mL}$ Hoagland solution (containing $1 / 10$ phosphate) every week. The clonal plants were grown in a greenhouse under natural light at a temperature of $25-35^{\circ} \mathrm{C}$ and a relative humidity of $50-75 \%$.

\subsection{Plant Harvest}

Height was measured with a flexible rule, ground diameter was measured with a digital caliper (Hengliang, Shanghai, China). Roots were divided into four parts after determining the fresh weight: the first part was used to determine AMF colonization; the second part was used to measure water content; the third part was used to measure element concentrations. After being ground into a powder in the liquid nitrogen, the fourth part was used for the RNA extraction, antioxidant enzyme activity determination, and malondialdehyde (MDA) concentration.

\subsection{Mycorrhizal Colonization}

After being stained with trypan blue [29], roots were used to determine mycorrhizal colonization by the gridline intersection method [30].

\subsection{Plant Biomass and Water Content}

The weight during the harvest process was regarded as the fresh weight. Roots were dried at $65{ }^{\circ} \mathrm{C}$ until constant weight to determine the dry weight. The dry weight and fresh weight were used to calculate the water content.

\subsection{Concentrations and Contents of $\mathrm{Na}^{+}, \mathrm{K}^{+}, \mathrm{Ca}^{2+}$, and $\mathrm{Cl}^{-}$}

After dried, roots were ground into powder. $\mathrm{Na}^{+}, \mathrm{K}^{+}$, and $\mathrm{Ca}^{2+}$ were extracted by $\mathrm{HNO}_{3}$ and a microwave digestion instrument (Milestone ETHOS, Milan, Italy), then measured using an atomic absorption spectrophotometer (PerkinElmer, Waltham, MA, USA). $\mathrm{Cl}^{-}$was extracted in boiling water [31] and measured by $\mathrm{AgCl}$ turbidimetry [32]. Element contents were calculated by the water content and fresh weight. Ten grams of air-dried soil $(<1 \mathrm{~mm})$ were placed in a $100 \mathrm{~mL}$ conical flask, to which $50 \mathrm{~mL}$ of water was added. After shaking for $3 \mathrm{~min}$, the mixture was filtered with a Buchner funnel to obtain a 5:1 water:soil leaching solution [33]. The concentrations of $\mathrm{Na}^{+}$and $\mathrm{Cl}^{-}$in soil were measured using the same methods used with roots.

\subsection{Antioxidant Enzyme Activities}

The method of superoxide dismutase (SOD) activity determination referred to the method of Mallick and Mohn [34]. Weigh $0.1 \mathrm{~g}$ of fresh root powder, add $4 \mathrm{~mL} \mathrm{of} \mathrm{pH}$ 7.8 pre-cooled phosphate buffer (PB), mix upside down, centrifuge at $4000 \mathrm{rpm}, 4{ }^{\circ} \mathrm{C}$ for $10 \mathrm{~min}$, transfer the supernatant to a new centrifuge tube. The reaction mixture was mixed with enzyme solution, $50 \mathrm{mM} \mathrm{PB}, 100 \mu \mathrm{M}$ EDTA- $\mathrm{Na}_{2}, 130 \mathrm{mM}$ methionine (Met), $750 \mu \mathrm{M}$ nitro blue tetrazolium (NBT), $20 \mu \mathrm{M}$ riboflavin. The absorbance value was measured at $560 \mathrm{~nm}\left(\mathrm{~A}_{560}\right)$. Take the amount of enzyme required to inhibit $50 \%$ of the NBT photore- 
duction reaction as an enzyme activity unit (U). SOD activity was calculated using the following formulas:

$$
\text { SOD activity }\left(\mathrm{U} \cdot \mathrm{g}^{-1} \mathrm{FW} \cdot \mathrm{min}^{-1}\right)=\frac{\left(A_{0}-A_{s}\right) \times V_{t}}{A_{0} \times 0.5 \times \mathrm{FW} \times V_{s} \times t}
$$

where $A_{0}$ is the absorbance of control tube under light; $A_{s}$, absorbance of sample tube; $V_{t}$, total volume of sample extract $(\mathrm{mL}) ; V_{S}$, volume of enzyme solution during measurement $(\mathrm{mL})$; $t$, light time of color reaction (min); FW, root fresh weight (g).

The method of peroxidase (POD) activity determination referred to the method of Fang and Kao [35]. Fresh root powder $(0.1 \mathrm{~g})$ was mixed with $4 \mathrm{~mL}$ pre-cooled distilled water. After being centrifuged at $4000 \mathrm{rpm}, 4{ }^{\circ} \mathrm{C}$ for $10 \mathrm{~min}$, the supernatant was the enzyme solution. The reaction mixture was mixed with enzyme solution, $0.1 \%$ guaiacol, and $0.18 \% \mathrm{H}_{2} \mathrm{O}_{2}$. The total volume was $6.3 \mathrm{~mL}$. The absorbance value was measured at $470 \mathrm{~nm}\left(A_{470}\right)$. POD activity was calculated using the following formulas:

$$
\text { POD activity }\left(\mu \mathrm{g} \cdot \mathrm{g}^{-1} \mathrm{FW} \cdot \mathrm{min}^{-1}\right)=\frac{\left(X-X_{0}\right) \times V_{t}}{\mathrm{FW} \times V_{s} \times t}
$$

where $X_{0}$ denotes the content of 4-Methoxyphenol in the control tube ( $\left.\mu \mathrm{g}\right) ; X, 4$-Methoxyphenol content in the sample tube calculated from the standard curve $(\mu \mathrm{g}) ; V_{t}$, total volume of sample extract $(\mathrm{mL}) ; V_{s}$, volume of enzyme solution during measurement $(\mathrm{mL}) ; t$, reaction time ( $\mathrm{min}) ; \mathrm{FW}$, root fresh weight (g).

\subsection{MDA Concentration}

MDA concentration was determined as described by Kramer et al. [36]. Weigh $0.1 \mathrm{~g}$ of fresh root powder, add $4 \mathrm{~mL} \mathrm{10 \%} \mathrm{trichloroacetic} \mathrm{acid} \mathrm{(TCA),} \mathrm{mix} \mathrm{upside} \mathrm{down,} \mathrm{centrifuge}$ at $4000 \mathrm{rpm}, 4{ }^{\circ} \mathrm{C}$ for $10 \mathrm{~min}$, transfer the supernatant to a new centrifuge tube. After adding $0.6 \%$ thiobarbituric acid (TBA), the mixture was heated in boiling water for $30 \mathrm{~min}$. The absorbance value was measured at 450,532 , and $600 \mathrm{~nm}\left(A_{450}, A_{532}, A_{600}\right)$. MDA concentration was calculated using the following formulas:

$$
\text { MDA concentration }\left(\mathrm{mmol} \cdot \mathrm{g}^{-1} \mathrm{FW}\right)=\left[6.452 \times\left(A_{532}-A_{600}\right)-0.559 \times A_{450}\right] \times \frac{V_{t}}{V_{s} \times \mathrm{FW}}
$$

where $V_{t}$ denotes the total volume of sample extract $(\mathrm{mL}) ; V_{s}$, volume of enzyme solution during measurement $(\mathrm{mL})$; FW, root fresh weight $(\mathrm{g})$.

\subsection{RNA Extraction, RNA-seq, and Bioinformatics Analysis}

Total RNA was extracted from roots using the E.Z.N.A Plant RNA Kit R6827-01 (Omega Bio-Tek, Norcross, GA, USA). The RNA samples were accepted when 260/280 ratios were determined as 1.9-2.1 using a Nano Photometer ${ }^{\circledR}$ spectrophotometer (IMPLEN, Westlake Village, CA, USA), with RIN value (RNA integrity number) $>6.0$ obtained using RNA Nano 6000 Assay Kit of the Bioanalyzer 2100 system (Agilent Technologies, CA, USA). Then, the RNA was sent to the Shanghai Personal Biotechnology Cp. Ltd. for RNA-Seq analysis (Personalbio, Shanghai, China). FastQC (version 0.11.8) (https://www.bioinformatics.babraham.ac.uk/projects/fastqc/, accessed on 8 January 2021) and Cutadapt (version 1.16) [37] were used to control the quality of original data. Trinity software (version 2.5.1) [38] was used to splice the transcript according to the default parameters. The longest sequence was used as the reference transcript sequence (Unigene) for subsequent analysis. The obtained Unigene was input in NR (NCBI non-redundant protein sequences), GO (Gene Ontology) [39], KEGG (Kyoto Encyclopedia of Genes and Genomes) [40], eggNOG (evolutionary genealogy of genes: Non-supervised Orthologous Groups) [41], Swiss-Prot (https:/ / www.ebi.ac.uk/uniprot/, accessed on 8 January 2021), and Pfam (http://pfam.xfam.org/, accessed on 8 January 2021) databases to compare the corresponding function annotations. RSEM software (version 1.2.15) [42] was used to perform quantitative analysis on Unigene. The obtained data were calculated using 
DEGseq (version 1.32.0) [43] in R language according to $\mid \log 2$ foldchang $\mid>1$ and $p$-value $<0.05$ to obtain differentially expressed genes (DEGs). Expression levels were estimated by fragments per kilobase of exon model per million mapped fragments (FPKM). The topGO (version 2.32.0) [44] software was used for GO enrichment analysis according to default parameters, while KEGG enrichment analysis was analyzed using the Parsons online analysis website (https:/ / www.genescloud.cn/chart/KEGGenrich, accessed on 8 January 2021) according to default parameters.

\subsection{Gene Expression Based on Quantitative Real-Time PCR ( $q R T-P C R$ )}

RNA was reverse transcribed to cDNA by a TIANScript RT Kit (TIANGEN Bio, Beijing, China). Eight genes, i.e., TRINITY_DN2270_c0_g2 (High-affinity $\mathrm{K}^{+}$transporter, HAK5), TRINITY_DN715_c1_g1 (K+ affinity transporter, KAT3), TRINITY_DN7186_c0_g3 (Shakertype $\mathrm{K}^{+}$outward rectifier, SKOR), TRINITY_DN5565_c0_g1 $\left(\mathrm{Na}^{+} / \mathrm{Ca}^{2+}\right.$ exchanger-like protein, NCL), TRINITY_DN3109_c3_g1 (Peroxidase 64, PER64), TRINITY_DN31653_c0_g1 (Putative cytochrome c peroxidase, CPER), TRINITY_DN13561_c0_g1 (Germin-like protein, GLP10), and TRINITY_DN22047_c0_g4 (Polyubiquitin, TU20), related to ion transport and antioxidant enzymes were randomly selected. The gene sequences were obtained from the assembly of the C. glauca RNA-seq using Illumina HiSeq technology (PRJNA690646). The primers used in the qRT-PCR, as described in Table S1, were designed with the NCBI Primer-BLAST tool. qRT-PCR was conducted using a CF96X real-time PCR system (BioRad, Hercules, CA, USA). Each reaction mixture was $10 \mu \mathrm{L}$ and contained $1 \mu \mathrm{L}$ diluted cDNA template, $0.5 \mu \mathrm{L}$ forward and reverse primers $(10 \mu \mathrm{M}), 5 \mu \mathrm{L}$ ChamQ SYBR qPCR Master Mix (Vazyme, Nanjing, China), and $3 \mu \mathrm{L}$ sterilized $\mathrm{ddH}_{2} \mathrm{O}$. The two-step qRT-PCR was run as follows: $30 \mathrm{~s}$ denaturation at $95{ }^{\circ} \mathrm{C}, 40$ cycles of denaturation at $95{ }^{\circ} \mathrm{C}$ for $10 \mathrm{~s}$, annealing at the annealing temperature for $10 \mathrm{~s}$, extension at $72{ }^{\circ} \mathrm{C}$ for $20 \mathrm{~s}$, followed by heating from 65 to $95^{\circ} \mathrm{C}$ at a rate of $0.5^{\circ} \mathrm{C}$ every $5 \mathrm{~s}$. All samples were performed two technical replicates. The relative expression level was determined using the $2^{-\Delta \Delta C_{T}}$ method [45].

\subsection{Statistical Analyses}

SPSS 26 statistical software (SPSS Inc., Chicago, IL, USA) was used for statistical analyses. All data were analysed by one-way ANOVA, post hoc comparisons (Tukey's test, $p<0.05, n=3)$, and two-way ANOVA ( $\mathrm{NaCl}$ stress, inoculation of $\mathrm{R}$. irregularis, and their interaction). Z-score was used to standardize the data and make a correlation curve for qRTPCR verification and RNA-Seq results. Figures were constructed with Origin 2020 (Origin Lab, Northampton, MA, USA). Heatmaps were generated with MetaboAnalyst (https: / /www.metaboanalyst.ca/?tdsour\%cetag=s_pctim_aiomsg, accessed on 3 July 2021).

\section{Results}

\subsection{Physiological and Biochemical Analysis in C. glauca Roots}

Under $\mathrm{NaCl}$ stress, inoculation with $R$. irregularis increased the fresh weight of shoots by $369 \%$, the fresh weight of roots by $265 \%$, the height by $116 \%$, and the ground diameter by $77 \%$. In mycorrhizal roots, $\mathrm{NaCl}$ stress reduced the colonization of arbuscule from $39 \%$ to $13 \%$ and increased the colonization of vesicle and spore from $34 \%$ to $57 \%$, but the difference in colonization of hypha was not significant $(p=0.053988)$. Under $\mathrm{NaCl}$ stress, inoculation with $R$. irregularis increased the $\mathrm{Na}^{+}, \mathrm{Cl}^{-}$content of roots by $234 \%$ and $260 \%$, but decreased the $\mathrm{Na}^{+}, \mathrm{Cl}^{-}$content of soil by $37 \%$ and $18 \%$. The $\mathrm{Na}^{+}, \mathrm{Cl}^{-}$concentrations of roots were increased by $\mathrm{NaCl}$ stress. However, inoculation with $R$. irregularis decreased the $\mathrm{Na}^{+}, \mathrm{Cl}^{-}$concentration of roots by $12 \%$ and $5 \%$ under $\mathrm{NaCl}$ stress. The contents of $\mathrm{K}^{+}$ and $\mathrm{Ca}^{2+}$ in roots were reduced by $\mathrm{NaCl}$ stress. However, under $\mathrm{NaCl}$ stress, inoculation with $R$. irregularis increased the content of $\mathrm{K}^{+}$and $\mathrm{Ca}^{2+}$ in roots by $338 \%$ and $183 \%$ and decreased $\mathrm{Na}^{+} / \mathrm{K}^{+}$and $\mathrm{Na}^{+} / \mathrm{Ca}^{2+}$ of roots by $24 \%$ and $31 \%$. Under $\mathrm{NaCl}$ stress, inoculation with $R$. irregularis decreased the MDA concentration of roots by $24 \%$. NaCl stress increased the activity of POD and SOD. However, under $\mathrm{NaCl}$ stress, inoculation with $R$. irregularis 
increased the activity of SOD in roots by $63 \%$, but the activity of POD was almost the same $(p=0.999971)$ (Table 1).

Table 1. Basic physiological and biochemical analysis of C. glauca $^{1}$.

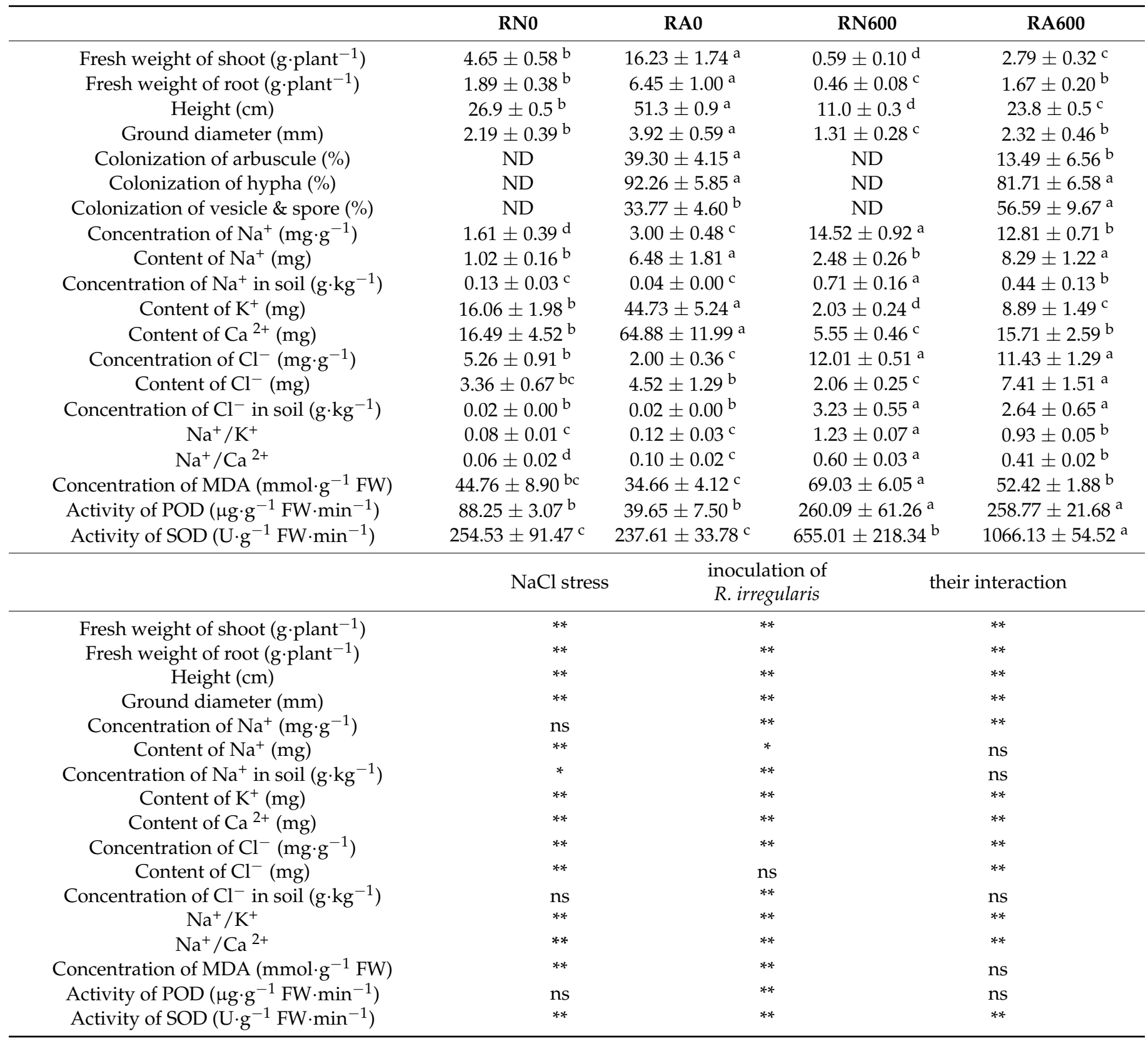

${ }^{1} \mathrm{R}$, roots; N, nonmycorrhizal; A, inoculated with R. irregularis; 0 , no $\mathrm{NaCl}$ stress; $600,600 \mathrm{mM} \mathrm{NaCl}$ stress. The data are the means \pm standard error $(n=3)$. Different superscript letters indicate significant differences among the means by Tukey's test $(p<0.05)$. Two-way ANOVA: "** indicates $p<0.05$, “**" indicates $p<0.01$, and "ns" indicates no significant difference $(p \geq 0.05)$.

\subsection{Summary of Sequencing Results}

In this study, RNA-seq was performed on 12 samples, and an average of $45,133,745$ raw reads was obtained. The average fuzzy base $(\mathrm{N})$ was $0.000348 \%$, the average Q20 was $97.67 \%$, and the average Q30 was $93.79 \%$. After strictly removing low-quality sequences, an average of 41,811,754 clean reads was obtained (Table S2).

After using Trinity software to splice and remove redundant sequences, a total of 58,988 sequences were obtained. The maximum sequence length was $20,358 \mathrm{bp}$, the average 
length was $1431.28 \mathrm{bp}$, the N50 value was $2832 \mathrm{bp}$, the N90 value was $525 \mathrm{bp}$, and the GC content was $40.77 \%$ (Table S3).

The obtained Unigene was annotated with gene function. There were $31,457,15,702$, $14,075,19,496,30,628$, and 26,164 sequences respectively annotated to NR, GO, KEGG, eggNOG, Pfam, and the Swiss-Prot databases (Table S4).

\subsection{Analysis of DEGs}

Under $\mathrm{NaCl}$ stress free condition, there were 3504 DEGs in RN0/RA0. Under noninoculated condition, RN0/RN600 had a total of 9017 DEGs, indicating that the number of $C$. glauca genes effected by $\mathrm{NaCl}$ stress was significantly greater than the number of genes effected by R. irregularis. There were 10,791 DEGs in RA0/RA600, which was more than non-mycorrhizal C. glauca, indicating that mycorrhizal C. glauca regulated more genes to help roots alleviate the damage of $\mathrm{NaCl}$ stress, or severe growth inhibition or transcriptional regulation has been damaged by $\mathrm{NaCl}$ stress in non-mycorrhizal C. glauca (Figure 1a). Under the conditions of inoculation and NaCl stress, RN600/RA600 had 850 DEGs (580, 92, and 178) up-regulated and 1485 DEGs $(1017,330$, and 138) down-regulated. These genes induced by $R$. irregularis under $\mathrm{NaCl}$ stress may help C. glauca to alleviate the damage of $\mathrm{NaCl}$ stress (Figure $1 \mathrm{~b}$ ).
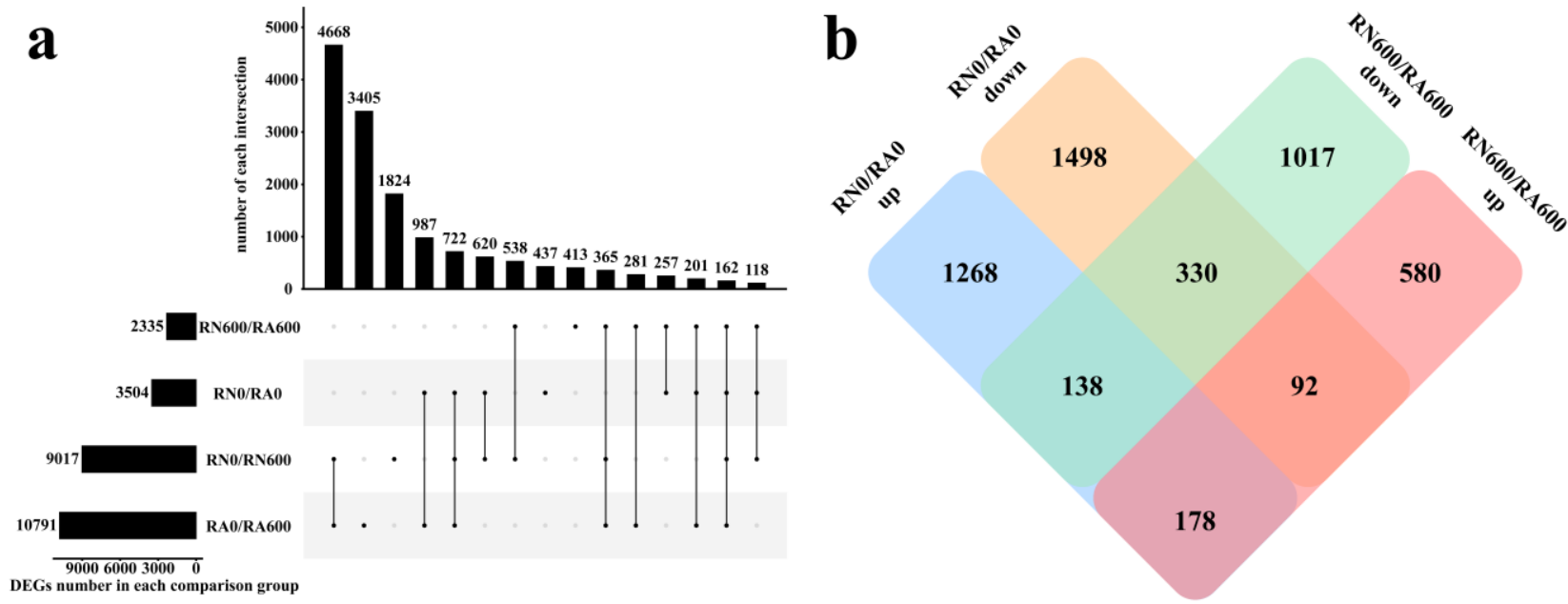

Figure 1. Upset diagram (a) and Venn diagram (b) of DEGs. R, roots; N, nonmycorrhizal; A, inoculated with $R$. irregularis; 0 , no $\mathrm{NaCl}$ stress; $600,600 \mathrm{mM} \mathrm{NaCl}$ stress. In Figure a, a point on the abscissa represents the number of unique DEGs annotated by the database; vertically connected points indicate the number of common DEGs annotated by multiple databases.

A total of 14,998 (4668, 3405, 1824, 987, 722, 620, 538, 437, 413, 365, 281, 257, 201, 162, and 118) DEGs were identified in the four comparison groups. In the comparison group with and without $R$. irregularis (RN0/RN600, RA0/RA600), NaCl stress adjusted a total of 13,891 DEGs $(4668,3405,1824,987,722,620,538,365,281,201,162$, and 118), of which a total of 5917 DEGs $(4668,722,365$, and 162) were found in both RN0/RN600 and RA0/RA600. The number of common DEGs accounted for about half of the total number of DEGs in each comparison group, showing the variable mechanism of $C$. glauca to $\mathrm{NaCl}$ stress during R. irregularis inoculation (Figure 1a).

Most of the DEGs under $\mathrm{NaCl}$ stress were different from those without $\mathrm{NaCl}$ stress. Hence, 508 DEGs (330 and 178) were not affected by $\mathrm{NaCl}$ stress to maintain the original difference trend, and these genes may be the key genes to maintain the symbiotic relationship. Moreover, 230 DEGs (138 and 92) showed opposite trends with and without $\mathrm{NaCl}$ stress, and they may be involved in the regulation of symbiotic relationships and response to $\mathrm{NaCl}$ stress. In addition, 1597 new DEGs (1017 and 580) were induced by R. irregularis under $\mathrm{NaCl}$ stress, which may be the genes in mycorrhizal C. glauca that specifically respond to 
$\mathrm{NaCl}$ stress. Therefore, 1827 DEGs (1597 new DEGs and 230 DEGs with opposite trends) were speculated to be involved in the process of $C$. glauca in response to $\mathrm{NaCl}$ stress under the inoculation of $R$. irregularis (Figure $1 \mathrm{~b}$ ).

\subsection{Analysis of GO, KEGG Enrichment}

By enriching and comparing DEGs in RN0/RN600 and RA0/RA600 respectively, it's helpful to clarify the similarities and differences between mycorrhizal and non-mycorrhizal C. glauca in response to $\mathrm{NaCl}$ stress. RN0/RN600 and RA0/RA600 were significantly enriched to 110 and $119 \mathrm{GO}$ terms, respectively, indicating that no matter with or without $R$. irregularis, $\mathrm{NaCl}$ stress would have a wide range of effects on $C$. glauca. The number of GO terms that were significantly enriched after inoculation with $R$. irregularis was less than that of non- $R$. irregularis, indicating that mycorrhizal C. glauca was under less stress than non-mycorrhizal C. glauca, or genes upregulated by mycorrhizal C. glauca were well worked to enhance salt tolerance. Among them, 88 GO terms appear in RN0/RN600 and RA0/RA600, mainly related to redox (such as "oxidoreductase activity, acting on diphenols and related substances as donors, oxygen as acceptor", "oxidoreductase activity") and antioxidation (such as "hydrogen peroxide metabolic process", "response to oxidative stress"), cell wall activity (such as "plant-type cell wall organization", "cell wall macromolecule metabolic process"), and metabolic process (such as "secondary metabolite biosynthetic process", "cellular carbohydrate metabolic process"), indicating that these pathways were the main pathways for $\mathrm{C}$. glauca to respond to $\mathrm{NaCl}$ stress. In these major pathways, the number of DEGs enriched by RA0/RA600 was often greater than that of RN0/RN600, indicating that $R$. irregularis could regulate more genes to help $C$. glauca relieve the damage of $\mathrm{NaCl}$ stress (Figure 2a). In addition, there were unique $\mathrm{GO}$ terms which were additionally significantly enriched in these two comparison groups, such as carbohydrate metabolism (such as "cellular carbohydrate biosynthetic process", "carbohydrate phosphatase activity") and plasma membrane (such as "integral component of plasma membrane", "anchored component of plasma membrane") in RN0/RN600 and "metal ion binding", "flavonoid biosynthetic process", and "carbohydrate binding" in RA0/RA600 (Figure 2b,c). This showed that the methods used to alleviate the damage of $\mathrm{NaCl}$ stress between mycorrhizal and non-mycorrhizal C. glauca were different.

To explore the role of $R$. irregularis in alleviating the damage of $\mathrm{NaCl}$ stress, $1827 \mathrm{DEGs}$ induced by $R$. irregularis in the RN600/RA600 were subjected to GO and KEGG enrichment analysis (Figure 3). These DEGs were significantly enriched in $59 \mathrm{GO}$ terms. Among them, the number of DEGs in metal ion binding and cation binding GO terms were the greatest. More DEGs were also significantly enriched in GO terms related to secondary metabolites (such as "secondary metabolite biosynthetic process", "secondary metabolic process"), antioxidant (such as "hydrogen peroxide metabolic process", "ROS metabolic process"), cell wall activities (such as "plant-type cell wall organization", "cell wall macromolecule metabolic process"), and ion transport (such as "calcium ion transmembrane transporter activity", "organic anion transmembrane transport"). Figure 3a presents the bubble chart of the 15 GO terms enriched with the most DEGs, implying the vigorous life activities in the mycorrhizal C. glauca.

In the KEGG enrichment analysis, all DEGs were enriched in 94 KEGG pathways. Among them, the most enriched DEGs in the "Ribosome" pathway also showed that the metabolism related to life activities in mycorrhizal C. glauca was relatively strong. The second enriched DEGs pathway is "phenylpropanoid biosynthesis". In addition, more DEGs were also enriched in "MAPK signaling pathway-plant" and "plant-pathogen interaction", implying that $C$. glauca is also actively maintaining an actively symbiotic relationship during $\mathrm{NaCl}$ stress. Figure $3 \mathrm{~b}$ presents the bubble chart of the 15 KEGG pathways enriched with the most DEGs. 

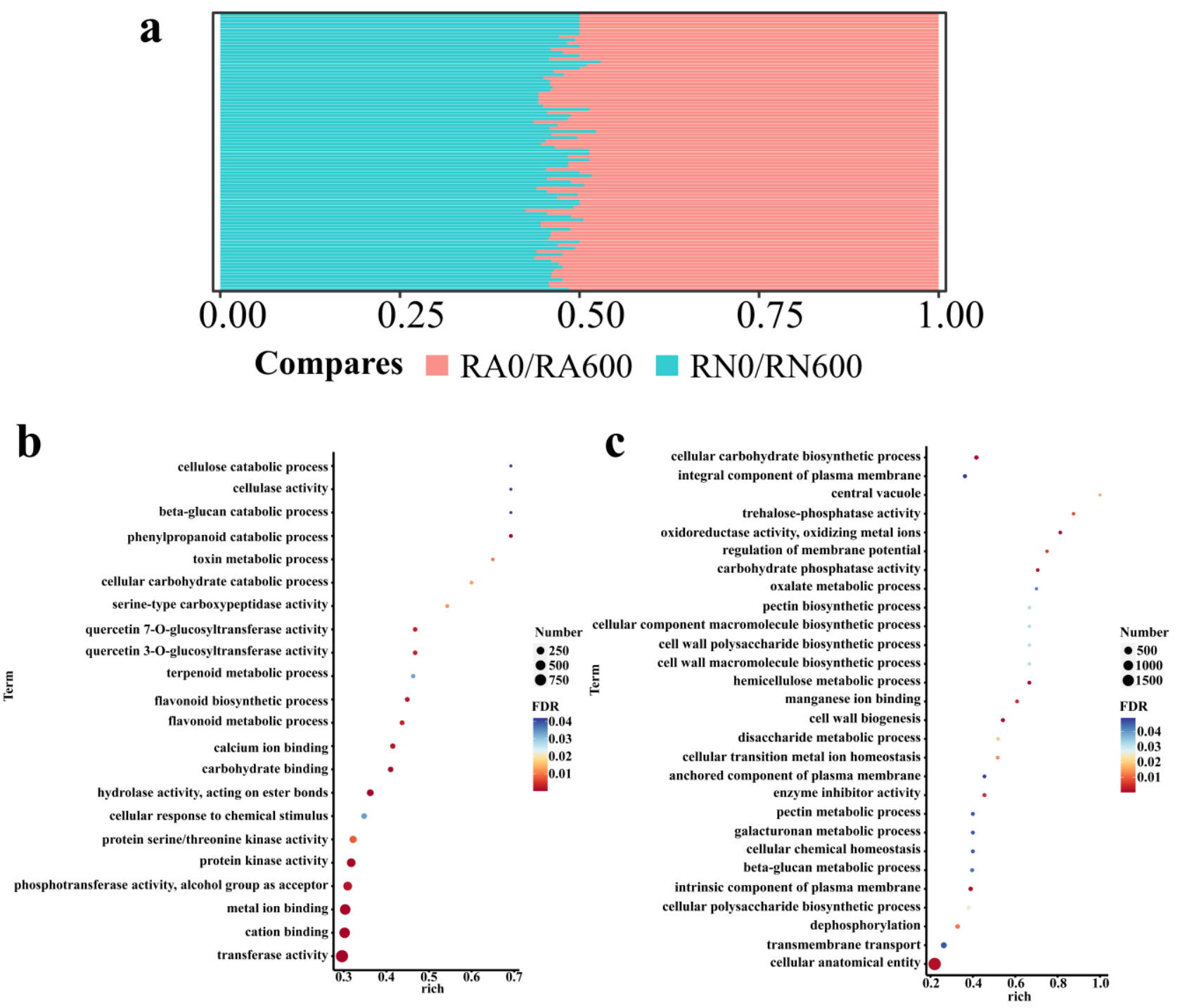

Figure 2. DEGs GO enrichment results in RA0/RA600 (b) and RN0/RN600 (c). R, roots; N, nonmycorrhizal; A, inoculated with $R$. irregularis; 0 , no NaCl stress; $600,600 \mathrm{mM} \mathrm{NaCl}$ stress. (a) The percentage of the DEGs number in each of the same 88 GO pathways in RA0/RA600 and RN0/RN600, compares represents the comparison group, the exact number and names of 88 GO pathways in RA0/RA600 and RN0/RN600 please refer to Table S5; (b) The bubble chart of 22 additional GO terms that were significantly enriched in RA0/RA600; (c) The bubble chart of 31 additional GO terms that were significantly enriched in RN0/RN600. Among them, the term represents the name of each channel, FDR represents the probability of enrichment, the number represents the number of DEGs contained in each channel, and rich represents the enrichment factor. 


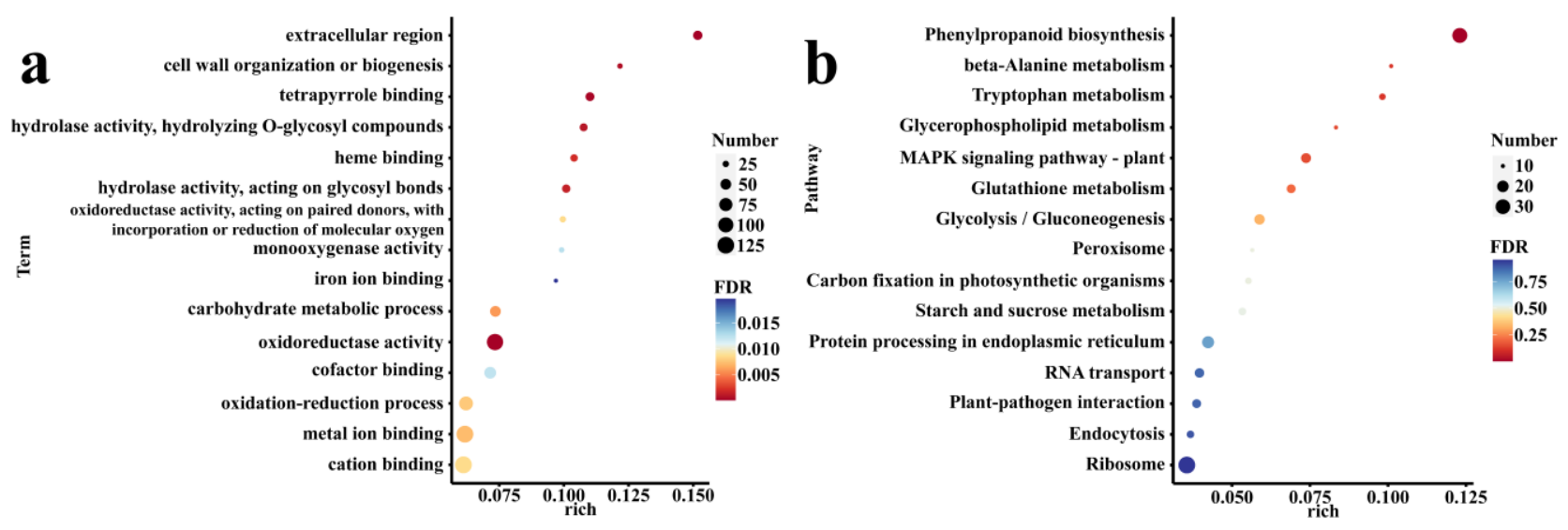

Figure 3. GO (a) and KEGG (b) enrichment of 1827 DEGs in response to $\mathrm{NaCl}$ stress induced by $R$. irregularis. (a) The bubble chart of the 15 GO terms enriched with the most DEGs; (b) the bubble chart of the 15 KEGG pathways enriched with the most DEGs. Among them, the term represents the name of each channel, FDR represents the probability of enrichment, the number represents the number of DEGs contained in each channel, and rich represents the enrichment factor.

\subsection{Response of DEGs Induced by R. irregularis under $\mathrm{NaCl}$ Stress}

To understand the molecular mechanism of $R$. irregularis in mitigating the damage of $\mathrm{NaCl}$ stress, the expression patterns related to ion balance transport and antioxidant enzymes were analyzed in RN600/RA600 (Figure 4). In RN600/RA600, only TRINITY_DN5565_c0_g1 (NCL) was found to be related to "sodium ion transmembrane transporter activity" and down-regulated, indicating that $R$. irregularis may inhibit the transmembrane transport of $\mathrm{Na}^{+}$. Three DEGs related to $\mathrm{K}^{+}$transport were identified, namely TRINITY_DN2270_c0_g2 (HAK5), TRINITY_DN715_c1_g1 (KAT3), and TRINITY_DN7186_c0_g3 $(S K O R)$. All of them were up-regulated by $R$. irregularis under $\mathrm{NaCl}$ stress. This implied that $R$. irregularis induced C. glauca to absorb a large amount of $\mathrm{K}^{+}$to balance the $\mathrm{Na}^{+} / \mathrm{K}^{+}$ under $\mathrm{NaCl}$ stress. In addition, a small amount of DEGs were also enriched in transporter related to calcium, iron, manganese, zinc, etc., but most of them showed a down-regulated state. In terms of anion transport, DEGs were mainly enriched in sulfate (four DEGs) and phosphate (three DEGs) transport. These anions may be important elements to maintain the balance of anion and cation in C. glauca under $\mathrm{NaCl}$ stress.

In the POD-related pathways, 16 DEGs were enriched. However, only three of them were up-regulated, while all the rest were down-regulated, implying that the regulation of POD synthesis was different in mycorrhizal and non-mycorrhizal C. glauca. The expression of TRINITY_DN3109_c3_g1 (PER64) and TRINITY_DN31653_c0_g1 (CPER) was greatly increased by $R$. irregularis under $\mathrm{NaCl}$ stress, suggesting that $R$. irregularis may increase POD content by inducing this gene. In the pathway related to SOD synthesis, two DEGs were enriched and TRINITY_DN13561_c0_g1 (GLP10) was significantly up-regulated, which may be related to the substantial increase of SOD content in roots.

TRINITY_DN74977_c0_g1 (NRT2-4), TRINITY_DN7435_c0_g1 (NPF4-6), and TRINITY_DN16482_c1_g1 (NPF1-2) were nitrate transporter (NRT) related genes in C. glauca and up-regulated by $R$. irregularis under $\mathrm{NaCl}$ stress, indicating that $R$. irregularis induced them to promote $\mathrm{N}$ uptake and ion balance in $\mathrm{C}$. glauca. At the same time, the expression of TRINITY_DN11775_c0_g1 (PIP1-2) and TRINITY_DN10056_c1_g1 (PIP2-7) was identified in RN600/RA600. Among them, TRINITY_DN11775_c0_g1 (PIP1-2) was significantly up-regulated by $R$. irregularis, suggesting that $R$. irregularis also played an important role in water transport under $\mathrm{NaCl}$ stress. 


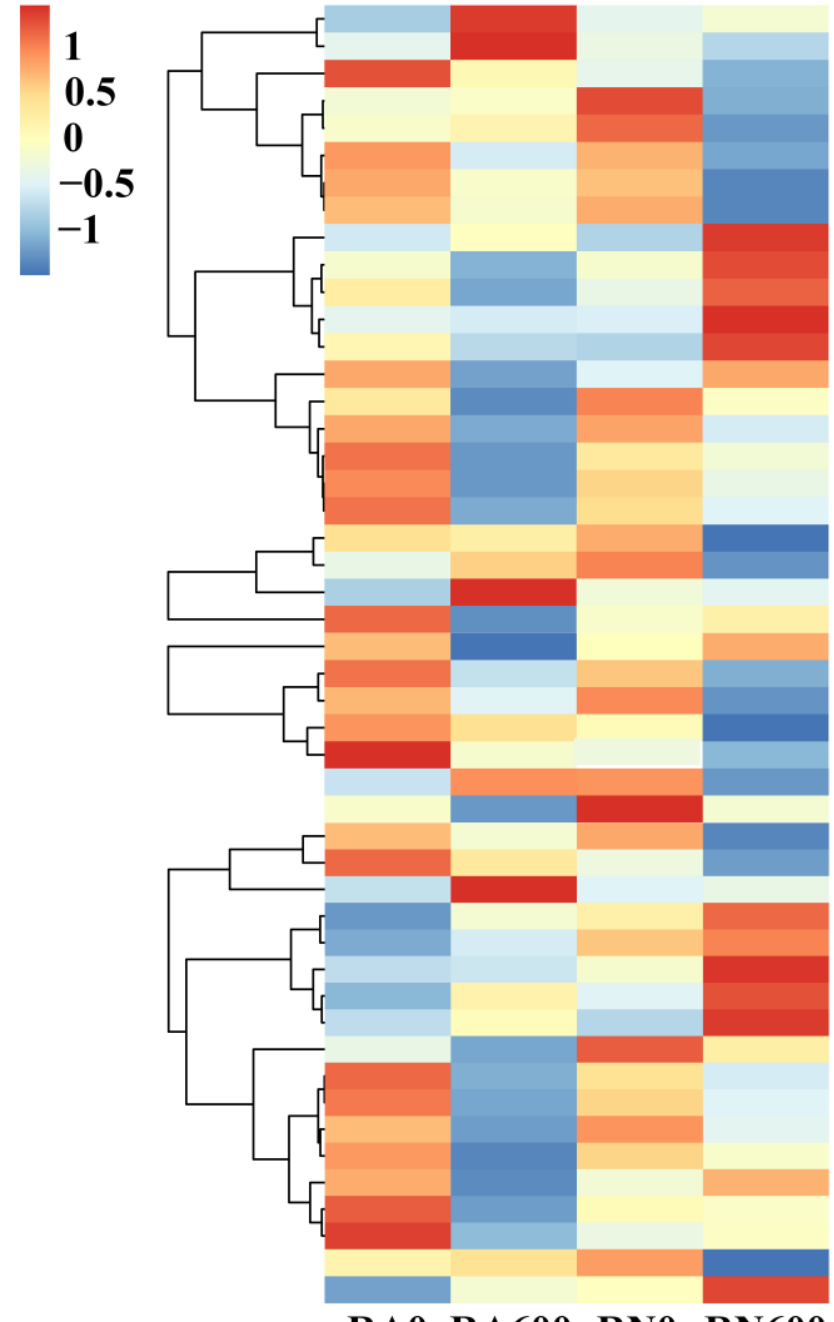

RA0 RA600 RNO RN600 TRINITY_DN7186_c0_g3 TRINITY DN2134_c4_g1 TRINITY DN715 $\overline{\mathrm{c}} 1 \overline{\mathrm{g}} \mathbf{1}$ TRINITY_DN15710_c0_g1 TRINITY_DN11584_c0_g1 TRINITY DN11867_c0_g1 TRINITY_DN1700_c0_g2 TRINITY DN5266 $\mathrm{c0}^{-\mathrm{g} 2}$ TRINITY DN1818 ${ }^{-} \overline{0}$ g1 TRINITY DN10977 c1 g1 TRINITY_DN13068_c0_g1 TRINITY_DN5565_c0_ $\mathbf{g} 1$ TRINITY DN7054_c0_g3 TRINITY_DN7340_c0_g1 TRINITY DN5504 c0 g2 TRINITY DN16047 c0 $\mathrm{g} 1$ TRINITY_DN4200 $\overline{\mathrm{c} 0} \mathrm{~g} 1$

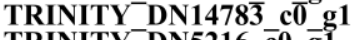
TRINITY_DN5216_c̄0_g1 TRINITY DN7915_c0_g1 TRINITY DN473 c0 TRINITY_DN2551_cōo_g1 TRINITY DN7435 $\mathrm{c0}_{\mathrm{g} 1}^{-}$ TRINITY_DN1648 $\overline{2}$ c $\overline{1}$ _g1 TRINITY_DN74977_c0_g1 TRINITY ${ }^{-}$DN20796 $\mathrm{c0}^{-} \mathrm{g} 3$ TRINITY DN11775-c0-g1 TRINITY_DN10056_c1_g1 TRINITY DN3109 $\overline{\mathrm{c}} 3 \overline{\mathrm{g}} 1$ TRINITY DN31653 TRINITY_DN8270 $\overline{\mathbf{c} 0} \overline{\mathrm{g} 1}$

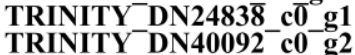
TRINITY-DN40092_c0_g2 TRINITY_DN40092_c0_g1 TRINITY DN42872_c0 g TRINITY DN5898 c0 $\mathbf{g} 1$ TRINITY DN78177 $\mathbf{c} \mathbf{0}$.g1 TRINITY DN1148 $\overline{\mathbf{c} 0} \overline{\mathrm{g} 1}$ TRINITY_DN78110_cōg1 TRINITY DN19662-c0-g1 TRINITY DN5672 $\overline{\mathrm{c} 0} \overline{\mathrm{g}} \mathrm{1}$ TRINITY DN3624- c0 $^{-}$-1 TRINITY DN84214 c0 g1 TRINITY DN13561_c0_g1 TRINITY DN22047 ${ }^{-} 0^{-} 4$
Potassium transport related Phosphorus transport related Potassium transport related Potassium transport related

Potassium transport related

Calcium transport related

Sulfur transport related

Sulfur transport related

Calcium and lead transport related

Cadmium, manganese, iron transport related

Sulfur transport related

Iron transport related

Phosphorus transport related

Sodium and calcium transport related

Phosphorus transport related

Zinc transport related

Sulfur transport related

Calcium transport related

Calcium transport related

ABC transporter related

ABC transporter related

ABC transporter related

Nitric acid transport related

Nitric acid transport related

Nitric acid transport related

Nitric acid transport related

Nitric acid transport related

Water transport related

Water transport related

POD related

POD related

POD related

POD related

POD related

POD related

POD related

POD related

POD related

POD related

POD related

POD related

POD related

POD related

POD related

POD related

SOD related

SOD related

Figure 4. Heat map of DEGs related to ion transport and antioxidant enzymes in different treatments. $\mathrm{R}$, roots; $\mathrm{N}$, nonmycorrhizal; $\mathrm{A}$, inoculated with $R$. irregularis; 0 , no $\mathrm{NaCl}$ stress; $600,600 \mathrm{mM}$ $\mathrm{NaCl}$ stress.

\subsection{Exploration of Transcription Factor Family Induced by R. irregularis}

In RN600/RA600, 55 DEGs in bHLH, ERF, MYB, MYB related, NAC, and WRKY transcription factor families have been identified (Figure 5). In these families, most DEGs were down-regulated, maybe because the roots of mycorrhizal C. glauca were less affected by $\mathrm{NaCl}$ stress. The expressions of TRINITY_DN76069_c0_g1 (ERF23), TRINITY_DN5601_c0_g2 (MYB46), TRINITY_DN21562_c0_g2 (NAC43), TRINITY_DN6778_c0_g1 (WRKY1), and TRINITY_DN3531_c0_g1 (WRKY19) in mycorrhizal C. glauca were higher than that of non-mycorrhizal C. glauca under $\mathrm{NaCl}$ stress. This showed that these DEGs are important in $\mathrm{NaCl}$ tolerance of $\mathrm{C}$. glauca induced by R. irregularis. 


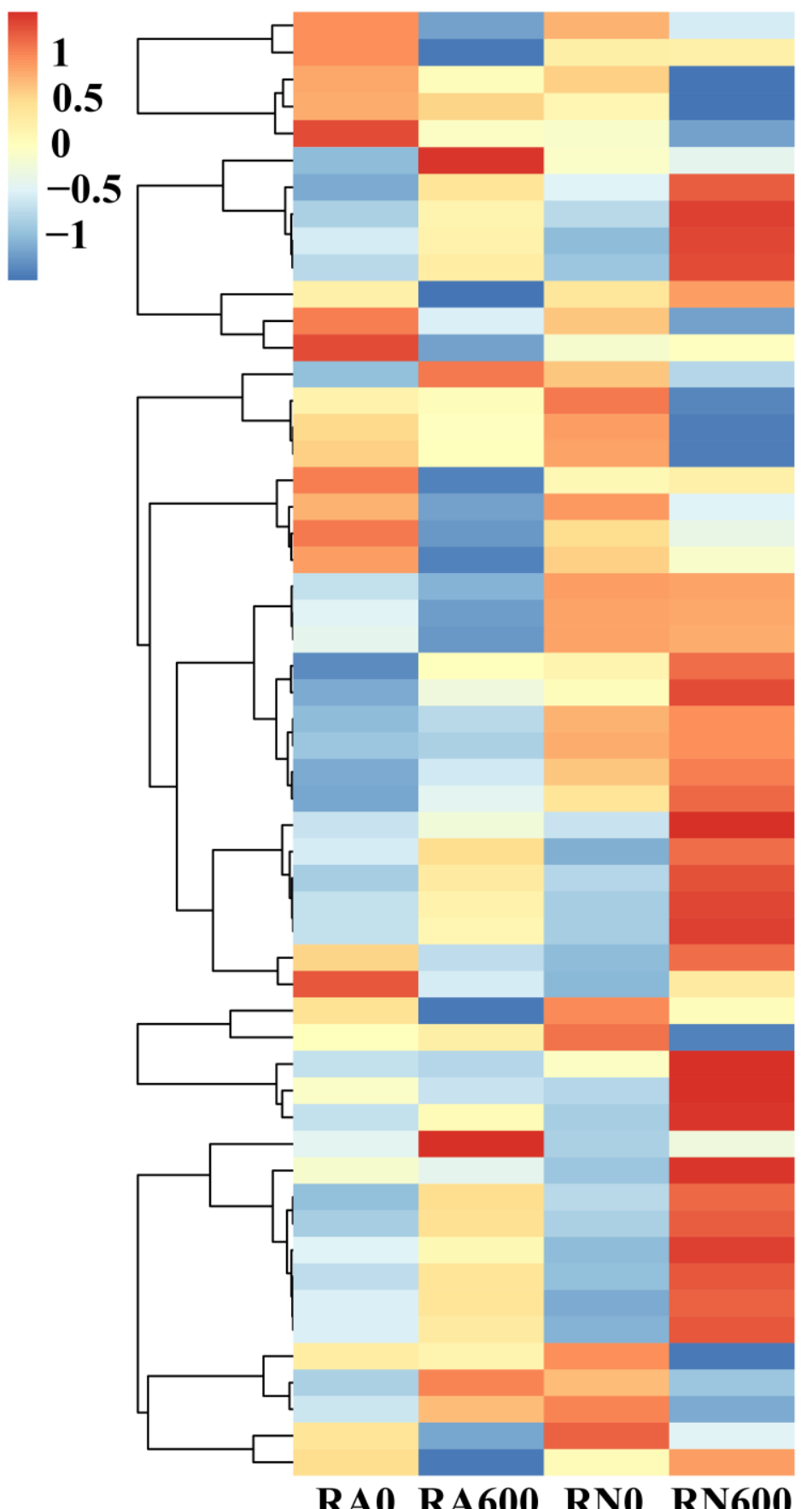

\begin{tabular}{|c|c|}
\hline 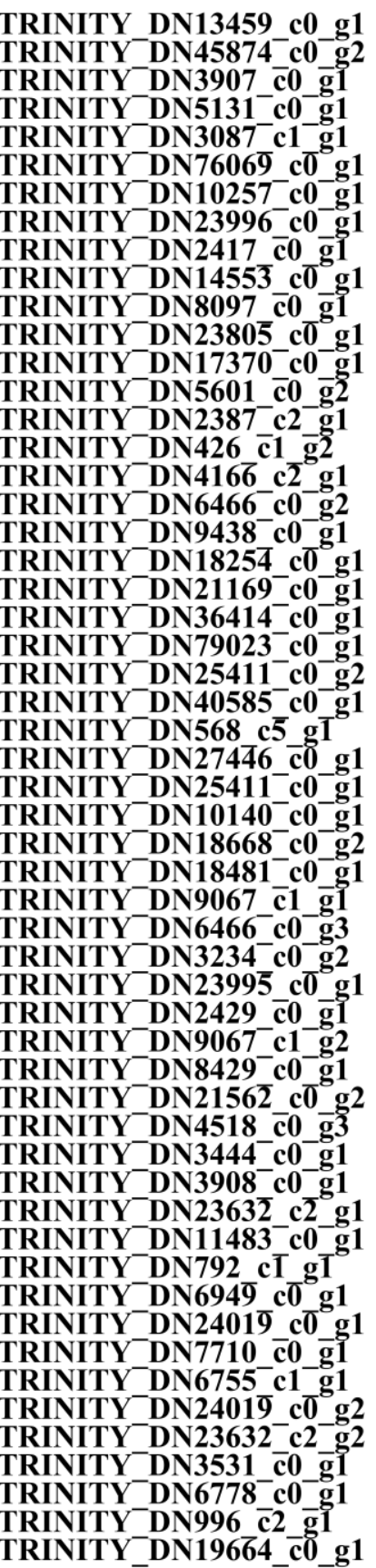 & $\begin{array}{l}\text { bHLH20 } \\
\text { bHLH41 } \\
\text { bHLH25 } \\
\text { bHLH61 } \\
\text { bHLH94 } \\
\text { ERF23 } \\
\text { ERF3 } \\
\text { ERF2 } \\
\text { ERF110 } \\
\text { ERF91 } \\
\text { ERF114 } \\
\text { ERF12 } \\
\text { ERF92 } \\
\text { MYB46 } \\
\text { MYB61 } \\
\text { MYB61 } \\
\text { MYB86 } \\
\text { MYB39 } \\
\text { MYB36 } \\
\text { MYB14 } \\
\text { MYB4 } \\
\text { MYB3R-1 } \\
\text { MYB64 } \\
\text { MYB-related } \\
\text { MYB118 } \\
\text { MYB36 } \\
\text { MYB2 } \\
\text { MYB-related } \\
\text { MYB3R-2 } \\
\text { MYB-related } \\
\text { MYB98 } \\
\text { MYB48 } \\
\text { MYB39 } \\
\text { MYB108 } \\
\text { MYB58 } \\
\text { MYB4 } \\
\text { MYB48 } \\
\text { NAC29 } \\
\text { NAC43 } \\
\text { NAC47 } \\
\text { NAC48 } \\
\text { NAC98 } \\
\text { WRKY19 } \\
\text { WRKY75 } \\
\text { WRKY75 } \\
\text { WRKY56 } \\
\text { WRKY56 } \\
\text { WRKY28 } \\
\text { WRKY28 } \\
\text { WRKY43 } \\
\text { WRKY19 } \\
\text { WRKY19 } \\
\text { WRKY1 } \\
\text { WRKY19 } \\
\text { WRKY49 }\end{array}$ \\
\hline
\end{tabular}

Figure 5. Heat map of DEGs related to transcription factors in different treatments. R, roots; N, nonmycorrhizal; A, inoculated with $R$. irregularis; 0 , no NaCl stress; $600,600 \mathrm{mM} \mathrm{NaCl}$ stress.

\subsection{The $q R T-P C R$ Verification}

To validate RNA-Seq data, TRINITY_DN2270_c0_g2 (HAK5), TRINITY_DN715_c1_g1 (KAT3), TRINITY_DN7186_c0_g3 (SKOR), TRINITY_DN5565_c0_g1 (NCL), TRINITY_DN 3109_c3_g1 (PER64), TRINITY_DN31653_c0_g1 (CPER), TRINITY_DN13561_c0_g1 (GLP10), and TRINITY_DN22047_c0_g4 (TU20) related to ion transport and antioxidant enzymes were randomly selected for qRT-PCR analysis. qRT-PCR and RNA-seq results of these eight genes were highly consistent (Pearson's $r=0.90979, p<0.01$ ) (Figure 6). This indicated that the results of transcriptome analysis were highly reliable. 


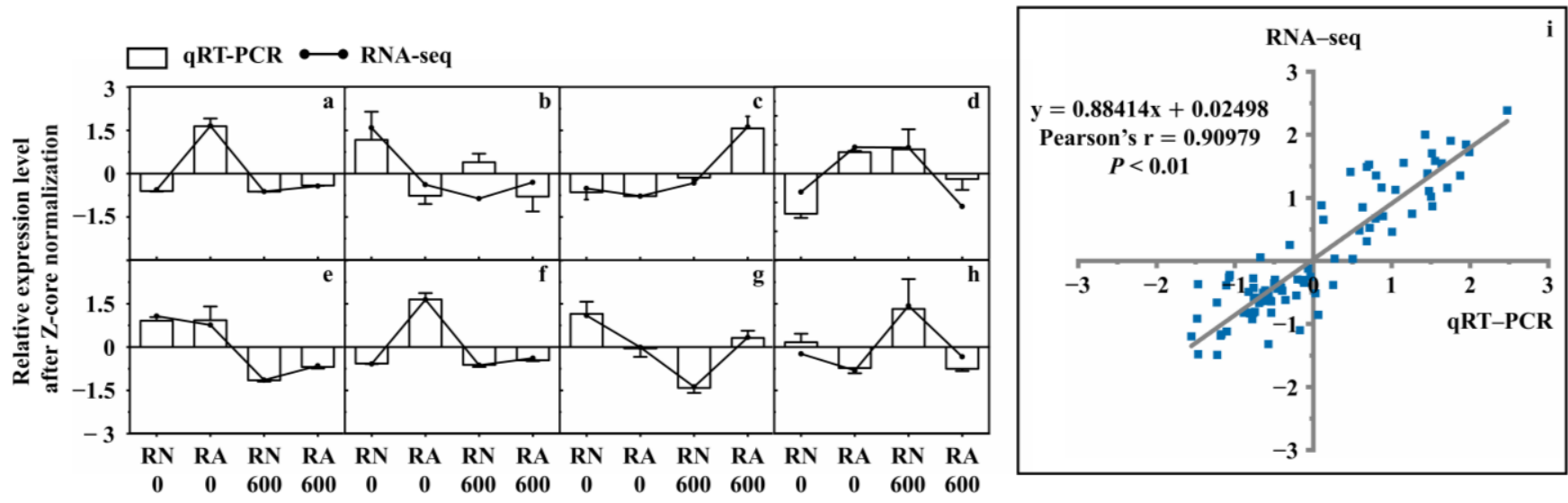

Figure 6. Correlation between qRT-PCR and RNA-Seq. R, roots; N, nonmycorrhizal; A, inoculated with $R$. irregularis; 0 , no $\mathrm{NaCl}$ stress; $600,600 \mathrm{mM} \mathrm{NaCl}$ stress. The relative expression level of each treatment was expressed as the change fold relative to RN0. (a) TRINITY_DN2270_c0_g2 (HAK5); (b) TRINITY_DN715_c1_g1 (KAT3); (c) TRINITY_DN7186_c0_g3 (SKOR); (d) TRINITY_DN5565_c0_g1 (NCL); (e) TRINITY_DN3109_c3_g1 (PER64); (f) TRINITY_DN31653_c0_g1 (CPER); (g) TRINITY_DN13561_c0_g1 (GLP10); (h) TRINITY_DN22047_c0_g4 (TU20). (i) Correlation curve of relative expression of 8 selected DEGs in roots between RNA-Seq and qRT-PCR. Standard error is represented by the error bars.

\section{Discussion}

Whether in crops (such as cucumber, corn, and wheat) [12,46,47] or forests (such as poplar, locust, and mulberry) [48-50], it has been confirmed that AMF can induce the host's systemic tolerance to $\mathrm{NaCl}$ stress by the maintenance of ion balance and increase of biomass and antioxidase activity. As a typical saline-alkali plant, C. glauca can tolerate high-salt environments [51]. Symbiosis between AMF and roots plays an important role in salt tolerance of C. glauca [4]. Studies on C. glauca have shown that the salt tolerance induced by AMF may be attributed to an improvement in ion levels, photosynthesis, water absorption, and plant morphology [21]. This study further revealed the contribution of $R$. irregularis in $\mathrm{NaCl}$ tolerance of mycorrhizal C. glauca by physiological, biochemical, and transcriptome analysis under $\mathrm{NaCl}$ stress.

In this study, inoculation with $R$. irregularis could significantly increase biomass, ameliorate the ratio of $\mathrm{Na}^{+}$to other metal cations, and increase antioxidant enzyme activity in C. glauca under $\mathrm{NaCl}$ stress. These findings are similar to those of Djighaly et al. [21], further confirming the importance of AMF in improving the salt tolerance of C. glauca. Under $\mathrm{NaCl}$ stress, the mycorrhizal C. glauca had a lower concentration but higher content of $\mathrm{Na}^{+}$than non-mycorrhizal C. glauca, which caused the lower $\mathrm{Na}^{+}$concentration in soil than non-mycorrhizal C. glauca but reduced the $\mathrm{NaCl}$ damage of mycorrhizal C. glauca. The results of transcriptome analysis showed that both $\mathrm{NaCl}$ stress and $\mathrm{R}$. irregularis can induce a large number of genetic changes in C. glauca, and a total of 14,998 DEGs were identified. Compared with control, $R$. irregularis inoculation could cause changes in 3504 DEGs. Most of these DEGs were related to ion transport, hormones, and antioxidase activities. These data confirmed the construction of the molecular-level interaction relationship between $R$. irregularis and C. glauca. In addition, 1827 DEGs were specifically affected by $R$. irregularis inoculation. Most of these DEGs were significantly enriched in ion transport, antioxidase activity, carbohydrate metabolism, cell wall, and other processes, indicating that they were important in enhancing the $\mathrm{NaCl}$ tolerance of $C$. glauca induced by R. irregularis.

\subsection{R. irregularis Inoculation Enhances the Ability to Remove the ROS of C. glauca under $\mathrm{NaCl}$ Stress}

Plants can produce excessive ROS when they are exposed to $\mathrm{NaCl}$ stress [52]. If ROS cannot be removed in time, it will cause membrane lipid peroxidation and other harms, 
which will damage normal cells [53]. Therefore, plants have evolved a set of antioxidant enzyme protection systems (such as SOD and POD) and non-enzymatic protection systems (such as ascorbic acid and carotenoids) [46]. They can effectively remove ROS to ensure the normal development of plants [54]. This study explored the effect of $R$. irregularis inoculation on MDA concentration and activities of SOD and POD. MDA is a by-product of membrane lipid peroxidation, and its content is often proportional to ROS content [55]. The results of our research are similar to most of the mycorrhizal plants under $\mathrm{NaCl}$ stress $[56,57]$. The inoculation with $R$. irregularis could reduce the MDA concentration of $C$. glauca under $\mathrm{NaCl}$ stress, indicating that $R$. irregularis inoculation can reduce the ROS in C. glauca under $\mathrm{NaCl}$ stress. $\mathrm{NaCl}$ stress increased the activity of SOD and POD in roots. When $R$. irregularis inoculation was present under $\mathrm{NaCl}$ stress, it significantly increased the activity of SOD in roots, but the POD activity was almost the same, indicating that mycorrhizal C. glauca seems to prefer SOD removal in the way of removing ROS under $\mathrm{NaCl}$ stress. This was probably because the POD activity per unit of fresh weight has reached the maximum. However, because the biomass of mycorrhizal C. glauca was more than non-mycorrhizal C. glauca, the content of SOD and POD in mycorrhizal C. glauca was higher. From a molecular perspective, under $\mathrm{NaCl}$ stress, there were also differences in the antioxidant enzyme synthesis between mycorrhizal and non-mycorrhizal C. glauca. Among the 1827 DEGs induced by $R$. irregularis in the roots, three of the 16 DEGs related to POD synthesis were identified, and one of the two DEGs related to SOD synthesis was upregulated. The expression of TRINITY_DN3109_c3_g1 (PER64), TRINITY_DN31653_c0_g1 (CPER), and TRINITY_DN13561_C0_g1 (GLP10) was greatly increased by $R$. irregularis inoculation under $\mathrm{NaCl}$ stress, indicating that these genes may be important in increasing the content of POD and SOD.

\subsection{R. irregularis Inoculation Promotes the Ion Absorption Capacity of C. glauca under $\mathrm{NaCl}$ Stress}

The root is the main organ for plants to absorb water and nutrients and it is also the first part damaged by salt [12]. Due to the presence of excess $\mathrm{Na}^{+}$around the roots, it hinders the absorption of other essential elements by roots, effecting the ion homeostasis and inhibiting growth of plants [58]. As the important symbiotic fungi in roots, AMF are mainly used to replace root hairs and assist plants in selectively absorbing mineral nutrients [59]. In our research, we found that inoculation with $R$. irregularis could increase the contents of $\mathrm{K}^{+}$and $\mathrm{Ca}^{2+}$ in $C$. glauca, reduce the $\mathrm{Na}^{+} / \mathrm{K}^{+}$and $\mathrm{Na}^{+} / \mathrm{Ca}^{2+}$, and maintain the ion balance in $C$. glauca. From a molecular perspective, genes related to the transport of $\mathrm{K}^{+}, \mathrm{Ca}^{2+}, \mathrm{SO}_{4}{ }^{2-}$, and $\mathrm{PO}_{4}{ }^{3-}$ were induced by $\mathrm{R}$. irregularis inoculation in mycorrhizal C. glauca under $\mathrm{NaCl}$ stress. These genes may be closely related to $R$. irregularis inoculation in maintaining ion balance of $C$. glauca under $\mathrm{NaCl}$ stress. Excessive $\mathrm{Na}^{+}$can compete with $\mathrm{K}^{+}$for binding sites on the lipid membrane around roots under $\mathrm{NaCl}$ stress, which hindered the absorption of $\mathrm{K}^{+}$[60]. Potassium deficiency can not only disrupt the ion balance but also inhibit growth of plants [61]. Research by Estrada et al. [10] found that $R$. irregularis could increase the $\mathrm{K}^{+}$content and reduce the $\mathrm{Na}^{+} / \mathrm{K}^{+}$of corn under $\mathrm{NaCl}$ stress, which also indicated that this phenomenon was related to changes in SKOR expression. HAK5 and KAT3 can also be up-regulated by $\mathrm{NaCl}$ stress to promote the absorption of $\mathrm{K}^{+}$by plants $[62,63]$. In our study, it was found that $R$. irregularis inoculation significantly increased TRINITY_DN2270_c0_g2 (HAK5), TRINITY_DN715_c1_g1 (KAT3), and TRINITY_DN7186_c0_g3 (SKOR) expression under $\mathrm{NaCl}$ stress. They may be the key genes for mycorrhizal C. glauca to maintain the $\mathrm{Na}^{+} / \mathrm{K}^{+}$balance, and it also indicates that mycorrhizal C. glauca can induce the HAK5 and KAT3 to promote the absorption of $\mathrm{K}^{+}$in C. glauca under $\mathrm{NaCl}$ stress.

Plant NRT participates in growth and the absorption and operation of nitrate nitrogen and other mineral ions of roots by regulating hormone transport and signal transduction, or as other ion transporters directly [64]. It also effects the plant tolerance under ion stresses [65]. In RN600/RA600, four genes in the five NRT families were up-regulated by $R$. irregularis inoculation, indicating that mycorrhizal C. glauca can promote nitrogen 
absorption to maintain ion balance and growth under $\mathrm{NaCl}$ stress. Overexpression of PIP12 in apples could improve drought and salt tolerance, reduce MDA content, and increase antioxidant enzyme activity [66]. In our study, $R$. irregularis inoculation further increased the expression of TRINITY_DN11775_c0_g1 (PIP1-2) in C. glauca under NaCl stress. This shows that PIP1-2 is important for mycorrhizal C. glauca to induce the $\mathrm{NaCl}$ tolerance.

\subsection{Regulation of Transcription Factors by R. irregularis Inoculation under $\mathrm{NaCl}$ Stress}

A transcription factor is a protein sequence that binds to specific DNA, which controls the transcription from DNA to mRNA, and is responsible for the expression of stressactivated genes for plant tolerance and adaptability [67]. bHLH, ERF, MYB, NAC, and WRKY are important transcription factor superfamilies in plants, which are involved in all aspects of plant growth and development, and have been proven to be important in salt tolerance [68]. We have found that a large number of genes related to cell wall pathways in plants are enriched during inoculation with $R$. irregularis under $\mathrm{NaCl}$ stress, which indicates that the development of cell walls and the degree of lignification are important to $\mathrm{NaCl}$ tolerance. Zhang et al. [69] found that inoculation with AMF could increase the salt tolerance by improving the development of roots' cell walls and the degree of lignification of Asparagus officinalis. MYB46 has been confirmed to be involved in the regulation of lignin synthesis in plants. The overexpression of MYB46 in apples can improve plant tolerance to salt and drought [70]. Yogendra et al. [71] found that MYB43 participated in the biosynthesis of plant secondary cell walls and promoted the synthesis and accumulation of phenylpropane metabolites. Our research also found that TRINITY_DN5601_c0_g2 (MYB46) and TRINITY_DN21562_c0_g2 (NAC43) were up-regulated in mycorrhizal C. glauca under $\mathrm{NaCl}$ stress, indicating that $R$. irregularis inoculation could promote the accumulation of lignin and the degree of lignification to improve $\mathrm{NaCl}$ tolerance of $C$. glauca. WRKY1 and WRKY19 are involved in hormone balance and salt adaptation in plants [72,73]. In our study, $R$. irregularis inoculation and $\mathrm{NaCl}$ stress jointly up-regulated TRINITY_DN6778_c0_g1 (WRKY1) and TRINITY_DN3531_c0_g1 (WRKY19), indicating that these two genes were important in the $\mathrm{NaCl}$ tolerance of mycorrhizal C. glauca.

\section{Conclusions}

The physiological and biochemical analysis showed that $R$. irregularis inoculation played an important role in promoting plant growth, regulating ion balance, and changing the activity of antioxidant enzymes. Transcriptome analysis of roots revealed that 1827 DEGs were affected by both $R$. irregularis inoculation and $\mathrm{NaCl}$ stress. Through the GO and KEGG enrichment analysis of these DEGs, it was found that $R$. irregularis inoculation improved the $\mathrm{NaCl}$ tolerance of $C$. glauca roots by regulating transcription factors, ion transport, antioxidase activity, carbohydrate metabolism, and cell wall. Our research focused on the ion transport, antioxidase activity, and transcription factors of C. glauca roots under $\mathrm{NaCl}$ stress, screening out the key genes related to these processes. The mycorrhizal C. glauca alleviated the damage of $\mathrm{NaCl}$ stress through HAK5, KAT3, SKOR, PIP1-2, PER64, CPER, GLP10, MYB46, NAC43, WRKY1, and WRKY19, providing molecular evidence that $R$. irregularis inoculation can assist C. glauca to relieve $\mathrm{NaCl}$ stress. This helps to visually express the salt tolerance mechanism induced by AMF and lays a foundation for the future use of AMF to enhance plant tolerance to salt stress.

Supplementary Materials: The following are available online at https:/ / www.mdpi.com/article/ 10.3390/microorganisms10010015/s1, Figure S1: The redox system of C. glauca under different treatments, Table S1: Primers used for quantitative real-time PCR (qRT-PCR), Table S2: Sequencing information of each group, Table S3: Transcript splicing information statistics, Table S4: Unigene annotation statistics results, Table S5: The exact number and names of 88 GO pathways in RA0/RA600 and RN0/RN600. 
Author Contributions: Conceptualization, Y.W. and F.D.; methodology and investigation, Y.W.; data curation, Y.W. and F.D.; writing — original draft preparation, F.D.; writing-review and editing, Y.W. and M.T.; supervision and project administration, M.T.; funding acquisition, M.T. All authors have read and agreed to the published version of the manuscript.

Funding: This research was funded by the Laboratory of Lingnan Modern Agriculture Project, grant number NZ2021025; the National Natural Science Foundation of China, and grant number 32071639.

Institutional Review Board Statement: Not applicable.

Informed Consent Statement: Not applicable.

Data Availability Statement: The data that support the findings of this study are available in NCBI at https:/ / www.ncbi.nlm.nih.gov/bioproject/, reference number is PRJNA690646.

Acknowledgments: We thank Chonglu Zhong from the Research Institute of Tropical Forestry, the Chinese Academy of Forestry for providing the seeds of $C$. glauca. We also would like to thank the three anonymous reviewers for their efforts in improving the manuscript.

Conflicts of Interest: The authors declare no conflict of interest.

\section{References}

1. Cirillo, V.; Masin, R.; Maggio, A.; Zanin, G. Crop-weed interactions in saline environments. Eur. J. Agron. 2018, 99, 51-61. [CrossRef]

2. Jiang, Z.H.; Zhou, X.P.; Tao, M.; Yuan, F.; Liu, L.L.; Wu, F.H.; Wu, X.M.; Xiang, Y.; Niu, Y.; Liu, F.; et al. Plant cell-surface GIPC sphingolipids sense salt to trigger $\mathrm{Ca}^{2+}$ influx. Nature 2019, 572, 341-346. [CrossRef]

3. Li, Y.; Niu, W.Q.; Cao, X.S.; Wang, J.W.; Zhang, M.Z.; Duan, X.H.; Zhang, Z.X. Effect of soil aeration on root morphology and photosynthetic characteristics of potted tomato plants (Solanum lycopersicum) at different $\mathrm{NaCl}$ salinity levels. BMC Plant Biol. 2019, 19, 331. [CrossRef] [PubMed]

4. Batista-Santos, P.; Duro, N.; Rodrigues, A.P.; Semedo, J.N.; Alves, P.; da Costa, M.; Graca, I.; Pais, I.P.; Scotti-Campos, P.; Lidon, F.C.; et al. Is salt stress tolerance in Casuarina glauca Sieb. ex Spreng. associated with its nitrogen-fixing root-nodule symbiosis? An analysis at the photosynthetic level. Plant Physiol. Biochem. 2015, 96, 97-109. [CrossRef]

5. Bharti, A.; Garg, N. SA and AM symbiosis modulate antioxidant defense mechanisms and asada pathway in chickpea genotypes under salt stress. Ecotoxicol. Environ. Saf. 2019, 178, 66-78. [CrossRef] [PubMed]

6. Evelin, H.; Devi, T.S.; Gupta, S.; Kapoor, R. Mitigation of Salinity Stress in Plants by Arbuscular Mycorrhizal Symbiosis: Current Understanding and New Challenges. Front. Plant Sci. 2019, 10, 470. [CrossRef]

7. Singh, H.; Kumar, P.; Kumar, A.; Kyriacou, C.M.; Colla, G.; Rouphael, Y. Grafting Tomato as a Tool to Improve Salt Tolerance. Agronomy 2020, 10, 263. [CrossRef]

8. $\quad$ Feng, S.; Sun, H.W.; Ma, H.P.; Zhang, X.; Ma, S.R.; Qiao, K.; Zhou, A.M.; Bu, Y.Y.; Liu, S.K. Sexual Differences in Physiological and Transcriptional Responses to Salinity Stress of Salix linearistipularis. Front. Plant Sci. 2020, 11, 517962. [CrossRef]

9. Castelan-Munoz, N.; Herrera, J.; Cajero-Sanchez, W.; Arrizubieta, M.; Trejo, C.; Garcia-Ponce, B.; Sanchez, M.P.; Alvarez-Buylla, E.R.; Garay-Arroyo, A. MADS-Box Genes Are Key Components of Genetic Regulatory Networks Involved in Abiotic Stress and Plastic Developmental Responses in Plants. Front. Plant Sci. 2019, 10, 853. [CrossRef] [PubMed]

10. Estrada, B.; Aroca, R.; Maathuis, F.J.; Barea, J.M.; Ruiz-Lozano, J.M. Arbuscular mycorrhizal fungi native from a Mediterranean saline area enhance maize tolerance to salinity through improved ion homeostasis. Plant Cell Environ. 2013, 36, 1771-1782. [CrossRef] [PubMed]

11. Kaur, S.; Suseela, V. Unraveling Arbuscular Mycorrhiza-Induced Changes in Plant Primary and Secondary Metabolome. Metabolites 2020, 10, 335. [CrossRef]

12. Santander, C.; Aroca, R.; Cartes, P.; Vidal, G.; Cornejo, P. Aquaporins and cation transporters are differentially regulated by two arbuscular mycorrhizal fungi strains in lettuce cultivars growing under salinity conditions. Plant Physiol. Biochem. 2021, 158, 396-409. [CrossRef]

13. Xu, J.; Liu, S.J.; Song, S.R.; Guo, H.L.; Tang, J.J.; Yong, W.H.J.; Ma, Y.D.; Chen, X. Arbuscular mycorrhizal fungi influence decomposition and the associated soil microbial community under different soil phosphorus availability. Soil Biol. Biochem. 2018, 120, 181-190. [CrossRef]

14. Vives-Peris, V.; de Ollas, C.; Gomez-Cadenas, A.; Perez-Clemente, R.M. Root exudates: From plant to rhizosphere and beyond. Plant. Cell Rep. 2020, 39, 3-17. [CrossRef]

15. Parvin, S.; Van Geel, M.; Yeasmin, T.; Verbruggen, E.; Honnay, O. Effects of single and multiple species inocula of arbuscular mycorrhizal fungi on the salinity tolerance of a Bangladeshi rice (Oryza sativa L.) cultivar. Mycorrhiza 2020, 30, 431-444. [CrossRef]

16. Diagne, N.; Ngom, M.; Djighaly, P.I.; Fall, D.; Hocher, V.; Svistoonoff, S. Roles of Arbuscular Mycorrhizal Fungi on Plant Growth and Performance: Importance in Biotic and Abiotic Stressed Regulation. Diversity 2020, 12, 370. [CrossRef]

17. Chandrasekaran, M. A Meta-Analytical Approach on Arbuscular Mycorrhizal Fungi Inoculation Efficiency on Plant Growth and Nutrient Uptake. Agriculture 2020, 10, 370. [CrossRef] 
18. Zhang, X.H.; Han, C.Z.; Gao, H.M.; Cao, Y.P. Comparative transcriptome analysis of the garden asparagus (Asparagus officinalis L.) reveals the molecular mechanism for growth with arbuscular mycorrhizal fungi under salinity stress. Plant Physiol. Biochem. 2019, 141, 20-29. [CrossRef] [PubMed]

19. Santander, C.; Aroca, R.; Ruiz-Lozano, J.M.; Olave, J.; Cartes, P.; Borie, F.; Cornejo, P. Arbuscular mycorrhiza effects on plant performance under osmotic stress. Mycorrhiza 2017, 27, 639-657. [CrossRef] [PubMed]

20. Ngom, M.; Gray, K.; Diagne, N.; Oshone, R.; Fardoux, J.; Gherbi, H.; Hocher, V.; Svistoonoff, S.; Laplaze, L.; Tisa, L.S.; et al. Symbiotic Performance of Diverse Frankia Strains on Salt-Stressed Casuarina glauca and Casuarina equisetifolia Plants. Front. Plant Sci. 2016, 7, 1331. [CrossRef] [PubMed]

21. Djighaly, P.I.; Diagne, N.; Ngom, M.; Ngom, D.; Hocher, V.; Fall, D.; Diouf, D.; Laplaze, L.; Svistoonoff, S.; Champion, A. Selection of arbuscular mycorrhizal fungal strains to improve Casuarina equisetifolia L. and Casuarina glauca Sieb. tolerance to salinity. Ann. For. Sci. 2018, 75, 72. [CrossRef]

22. Djighaly, P.I.; Ngom, D.; Diagne, N.; Fall, D.; Ngom, M.; Diouf, D.; Hocher, V.; Laplaze, L.; Champion, A.; Farrant, J.M.; et al. Effect of Casuarina Plantations Inoculated with Arbuscular Mycorrhizal Fungi and Frankia on the Diversity of Herbaceous Vegetation in Saline Environments in Senegal. Diversity 2020, 12, 293. [CrossRef]

23. Fan, C.; Qiu, Z.; Zeng, B.; Li, X.; Xu, S.H. Physiological adaptation and gene expression analysis of Casuarina equisetifolia under salt stress. Biol. Plantarum. 2018, 62, 489-500. [CrossRef]

24. Zhang, Y.; Zhong, C.L.; Chen, Y.; Chen, Z.; Jiang, Q.B.; Wu, C.; Pinyopusarerk, K. Improving drought tolerance of Casuarina equisetifolia seedlings by arbuscular mycorrhizas under glasshouse conditions. New For. 2010, 40, 261-271. [CrossRef]

25. Li, J.L.; Cui, J.; Dai, C.H.; Liu, T.J.; Cheng, D.Y.; Luo, C.F. Whole-Transcriptome RNA Sequencing Reveals the Global Molecular Responses and CeRNA Regulatory Network of mRNAs, lncRNAs, miRNAs and circRNAs in Response to Salt Stress in Sugar Beet (Beta vulgaris). Int. J. Mol. Sci. 2020, 22, 289. [CrossRef] [PubMed]

26. Liu, J.G.; Han, X.; Yang, T.; Cui, W.H.; Wu, A.M.; Fu, C.X.; Wang, B.C.; Liu, L.J. Genome-wide transcriptional adaptation to salt stress in Populus. BMC Plant Biol. 2019, 19, 367. [CrossRef]

27. Ye, W.B.; Wang, T.T.; Wei, W.; Lou, S.T.; Lan, F.X.; Zhu, S.; Li, Q.Z.; Ji, G.L.; Lin, C.T.; Wu, X.H.; et al. The Full-Length Transcriptome of Spartina alterniflora Reveals the Complexity of High Salt Tolerance in Monocotyledonous Halophyte. Plant Cell Physiol. 2020, 61, 882-896. [CrossRef]

28. Li, B.S.; Duan, H.; Li, J.G.; Deng, X.W.; Yin, W.L.; Xia, X.L. Global identification of miRNAs and targets in Populus euphratica under salt stress. Plant Mol. Biol. 2013, 81, 525-539. [CrossRef]

29. Phillips, J.M.; Hayman, D.S. Improved procedures for clearing roots and staining parasitic and vesicular-arbuscular mycorrhizal fungi for rapid assessment of infection. Trans. Br. Myco. Soc. 1970, 55, 158-161. [CrossRef]

30. Giovannetti, M.; Mosse, B. An evaluation of techniques for measuring vesicular arbuscular mycorrhizal infection in roots. New Phytol. 1980, 84, 489-500. [CrossRef]

31. Matsushita, N.; Matoh, T. Characterization of $\mathrm{Na}^{+}$exclusion mechanisms of salt-tolerant reed plants in comparison with salt-sensitive rice plants. Physiol. Plantarum. 1991, 83, 170-176. [CrossRef]

32. Zhan, X.C.; Li, C.R.; Li, Z.Y.; Yang, X.C.; Zhong, S.G.; Yi, T. Highly Accurate Nephelometric Titrimetry. J. Pharm Sci. 2004, 93, 441-448. [CrossRef] [PubMed]

33. Bao, S.D. Soil Agricultural Chemistry Analysis, 3rd ed.; China Agricultural Press: Beijing, China, 2000.

34. Mallick, N.; Mohn, F.H. Reactive oxygen species: Response of algal cells. J. Plant Physiol. 2000, 157, 183-193. [CrossRef]

35. Fang, W.C.; Kao, C.H. Enhanced peroxidase activity in rice leaves in response to excess iron, copper and zinc. Plant Sci. 2000, 158, 71-76. [CrossRef]

36. Kramer, G.F.; Norman, H.A.; Krizek, D.T.; Mirecki, R.M. influence of UV-B radiation on polyamines, lipid peroxidation and membrane lipids in cucumber. Phytochemistry 1991, 30, 2101-2108. [CrossRef]

37. Martin, M. Cutadapt removes adapter sequences from high-throughput sequencing reads. EMBnet J. 2011, 17, 10-12. [CrossRef]

38. Grabherr, M.G.; Haas, B.J.; Yassour, M.; Levin, J.Z.; Thompson, D.A.; Amit, I.; Adiconis, X.; Fan, L.; Raychowdhury, R.; Zeng, Q.; et al. Full-length transcriptome assembly from RNA-Seq data without a reference genome. Nat. Biotechnol. 2011, 29, 644-652. [CrossRef]

39. Ashburner, M.; Ball, C.A.; Blake, J.A.; Botstein, D.; Butler, H.; Cherry, J.M.; Davis, A.P.; Dolinski, K.; Dwight, S.S.; Eppig, J.T.; et al Gene Ontology: Tool for the unification of biology. Nat. Genet. 2000, 25, 25-29. [CrossRef]

40. Kanehisa, M.; Araki, M.; Goto, S.; Hattori, M.; Hirakawa, M.; Itoh, M.; Katayama, T.; Kawashima, S.; Okuda, S.; Tokimatsu, T.; et al. KEGG for linking genomes to life and the environment. Nucleic Acids Res. 2008, 36, D480-D484. [CrossRef]

41. Powell, S.; Szklarczyk, D.; Trachana, K.; Roth, A.; Kuhn, M.; Muller, J.; Arnold, R.; Rattei, T.; Letunic, I.; Doerks, T.; et al. eggNOG v3.0: Orthologous groups covering 1133 organisms at 41 different taxonomic ranges. Nucleic Acids Res. 2012, 40, D284-D289. [CrossRef]

42. Li, B.; Dewey, C.N. RSEM: Accurate transcript quantification from RNA-Seq data with or without a reference genome. BMC Bioinform. 2011, 12, 16. [CrossRef] [PubMed]

43. Wang, L.K.; Feng, Z.X.; Wang, X.; Wang, X.W.; Zhang, X.G. DEGseq: An R package for identifying differentially expressed genes from RNA-seq data. Bioinformatics 2010, 26, 136-138. [CrossRef]

44. Alexa, A.; Rahnenfuhrer, J.; Lengauer, T. Improved scoring of functional groups from gene expression data by decorrelating GO graph structure. Bioinformatics 2006, 22, 1600-1607. [CrossRef] [PubMed] 
45. Livak, K.J.; Schmittgen, T.D. Analysis of relative gene expression data using real-time quantitative PCR and the 2(-Delta Delta C(T)) Method. Methods 2001, 25, 402-408. [CrossRef] [PubMed]

46. Hashem, A.; Alqarawi, A.A.; Radhakrishnan, R.; Al-Arjani, A.F.; Aldehaish, H.A.; Egamberdieva, D.; Abd Allah, E.F. Arbuscular mycorrhizal fungi regulate the oxidative system, hormones and ionic equilibrium to trigger salt stress tolerance in Cucumis sativus L. Saudi J. Biol. Sci. 2018, 25, 1102-1114. [CrossRef] [PubMed]

47. Eroglu, C.G.; Cabral, C.; Ravnskov, S.; Bak Topbjerg, H.; Wollenweber, B. Arbuscular mycorrhiza influences carbon-use efficiency and grain yield of wheat grown under pre- and post-anthesis salinity stress. Plant Biol. 2020, 22, 863-871. [CrossRef]

48. Wu, N.; Li, Z.; Wu, F.; Tang, M. Comparative photochemistry activity and antioxidant responses in male and female Populus cathayana cuttings inoculated with arbuscular mycorrhizal fungi under salt. Sci. Rep. 2016, 6, 37663. [CrossRef] [PubMed]

49. Chen, J.; Zhang, H.Q.; Zhang, X.L.; Tang, M. Arbuscular Mycorrhizal Symbiosis Alleviates Salt Stress in Black Locust through Improved Photosynthesis, Water Status, and $\mathrm{K}^{+} / \mathrm{Na}^{+}$Homeostasis. Front. Plant Sci. 2017, 8, 1739. [CrossRef]

50. Wang, Y.H.; Zhang, N.L.; Wang, M.Q.; He, X.B.; Lv, Z.Q.; Wei, J.; Su, X.; Wu, A.P.; Li, Y. Sex-Specific Differences in the Physiological and Biochemical Performance of Arbuscular Mycorrhizal Fungi-Inoculated Mulberry Clones Under Salinity Stress. Front. Plant Sci. 2021, 12, 614162. [CrossRef]

51. Mansour, S.R.; Abdel-lateif, K.; Bogusz, D.; Franche, C. Influence of salt stress on inoculated Casuarina glauca seedlings. Symbiosis 2016, 70, 129-138. [CrossRef]

52. Mushke, R.; Yarra, R.; Kirti, P.B. Improved salinity tolerance and growth performance in transgenic sunflower plants via ectopic expression of a wheat antiporter gene (TaNHX2). Mol. Biol. Rep. 2019, 46, 5941-5953. [CrossRef] [PubMed]

53. Fan, Y.F.; Wan, S.M.; Jiang, Y.S.; Xia, Y.Q.; Chen, X.H.; Gao, M.Z.; Cao, Y.X.; Luo, Y.H.; Zhou, Y.; Jiang, X.Y. Over-expression of a plasma membrane $\mathrm{H}^{+}$-ATPase SpAHA1 conferred salt tolerance to transgenic Arabidopsis. Protoplasma 2018, 255, 1827-1837. [CrossRef] [PubMed]

54. Nath, M.; Bhatt, D.; Prasad, R.; Tuteja, N. Reactive Oxygen Species (ROS) Metabolism and Signaling in Plant-Mycorrhizal Association Under Biotic and Abiotic Stress Conditions. In Mycorrhiza-Eco-Physiology, Secondary Metabolites, Nanomaterials, Springer International Publishing: New York, NY, USA, 2017; pp. 223-232. [CrossRef]

55. Navarro, J.M.; Perez-Tornero, O.; Morte, A. Alleviation of salt stress in citrus seedlings inoculated with arbuscular mycorrhizal fungi depends on the rootstock salt tolerance. J. Plant Physiol. 2014, 171, 76-85. [CrossRef] [PubMed]

56. Elgharably, A.; Nafady, N.A. Inoculation with Arbuscular mycorrhizae, Penicillium funiculosum and Fusarium oxysporum enhanced wheat growth and nutrient uptake in the saline soil. Rhizosphere 2021, 18, 100345. [CrossRef]

57. Hidri, R.; Mahmoud, O.M.B.; Farhat, N.; Cordero, I.; Pueyo, J.J.; Debez, A.; Barea, J.M.; Abdelly, C.; Azcon, R. Arbuscular mycorrhizal fungus and rhizobacteria affect the physiology and performance of Sulla coronariaplants subjected to salt stress by mitigation of ionic imbalance. J. Plant Nutr. Soil Sci. 2019, 182, 451-462. [CrossRef]

58. Park, Y.C.; Lim, S.D.; Moon, J.C.; Jang, C.S. A rice really interesting new gene H2-type E3 ligase, OsSIRH2-14, enhances salinity tolerance via ubiquitin/26S proteasome-mediated degradation of salt-related proteins. Plant Cell Environ. 2019, 42, 3061-3076. [CrossRef]

59. Zhou, X.Q.; Li, J.Y.; Tang, N.W.; Xie, H.Y.; Fan, X.N.; Chen, H.; Tang, M.; Xie, X. Genome-Wide Analysis of Nutrient Signaling Pathways Conserved in Arbuscular Mycorrhizal Fungi. Microorganisms 2021, 9, 1557. [CrossRef] [PubMed]

60. Wang, L.; Liu, Y.H.; Li, D.; Feng, S.J.; Yang, J.W.; Zhang, J.J.; Zhang, J.L.; Wang, D.; Gan, Y.T. Improving salt tolerance in potato through overexpression of AtHKT1 gene. BMC Plant Biol. 2019, 19, 357. [CrossRef]

61. Yang, Y.N.; Jiang, H.; Wang, M.L.; Korpelainen, H.; Li, C.Y. Male poplars have a stronger ability to balance growth and carbohydrate accumulation than do females in response to a short-term potassium deficiency. Physiol. Plant 2015, 155, 400-413. [CrossRef]

62. Huertas, R.; Rubio, L.; Cagnac, O.; Garcia-Sanchez, M.J.; Alche Jde, D.; Venema, K.; Fernandez, J.A.; Rodriguez-Rosales, M.P. The $\mathrm{K}^{+} / \mathrm{H}^{+}$antiporter LeNHX2 increases salt tolerance by improving $\mathrm{K}^{+}$homeostasis in transgenic tomato. Plant Cell Environ. 2013, 36, 2135-2149. [CrossRef]

63. Yaish, M.W.; Al-Lawati, A.; Al-Harrasi, I.; Patankar, H.V. Genome-wide DNA Methylation analysis in response to salinity in the model plant caliph medic (Medicago truncatula). BMC Genom. 2018, 19, 78. [CrossRef]

64. Zhang, G.B.; Meng, S.; Gong, J.M. The Expected and Unexpected Roles of Nitrate Transporters in Plant Abiotic Stress Resistance and Their Regulation. Int. J. Mol. Sci. 2018, 19, 3535. [CrossRef]

65. Fan, X.R.; Naz, M.; Fan, X.R.; Xuan, W.; Miller, J.A.; Xu, G.H. Plant nitrate transporters: From gene function to application. J. Exp. Bot. 2017, 68, 2463-2475. [CrossRef]

66. Liu, H.L.; Yang, L.L.; Xin, M.M.; Ma, F.W.; Liu, J.Y. Gene-Wide Analysis of Aquaporin Gene Family in Malus domestica and Heterologous Expression of the Gene MpPIP2;1 Confers Drought and Salinity Tolerance in Arabidposis thaliana. Int. J. Mol. Sci. 2019, 20, 3710. [CrossRef] [PubMed]

67. Du, X.L.; Wang, G.; Ji, J.; Shi, L.P.; Guan, C.F.; Jin, C. Comparative transcriptome analysis of transcription factors in different maize varieties under salt stress conditions. Plant Growth Regul. 2016, 81, 183-195. [CrossRef]

68. Cheng, P.L.; Gao, J.J.; Feng, Y.T.; Zhang, Z.X.; Liu, Y.N.; Fang, W.M.; Chen, S.M.; Chen, F.D.; Jiang, J.F. The chrysanthemum leaf and root transcript profiling in response to salinity stress. Gene 2018, 674, 161-169. [CrossRef] [PubMed]

69. Zhang, X.H.; Gao, H.M.; Liang, Y.Q.; Cao, Y.P. Full-length transcriptome analysis of asparagus roots reveals the molecular mechanism of salt tolerance induced by arbuscular mycorrhizal fungi. Environ. Exp. Bot. 2021, 185, 104402. [CrossRef] 
70. Chen, K.Q.; Song, M.R.; Guo, Y.N.; Liu, L.F.; Xue, H.; Dai, H.Y.; Zhang, Z.H. MdMYB46 could enhance salt and osmotic stress tolerance in apple by directly activating stress-responsive signals. Plant Biotechnol. J. 2019, 17, 2341-2355. [CrossRef] [PubMed]

71. Yogendra, K.N.; Sarkar, K.; Kage, U.; Kushalappa, A.C. Potato NAC43 and MYB8 Mediated Transcriptional Regulation of Secondary Cell Wall Biosynthesis to Contain Phytophthora infestans Infection. Plant Mol. Biol. Rep. 2017, 35, 519-533. [CrossRef]

72. Shen, Z.D.; Yao, J.; Sun, J.; Chang, L.W.; Wang, S.J.; Ding, M.Q.; Qian, Z.Y.; Zhang, H.L.; Zhao, N.; Sa, G.; et al. Populus euphratica HSF binds the promoter of WRKY1 to enhance salt tolerance. Plant Sci. 2015, 235, 89-100. [CrossRef]

73. Çatav, S..S.; Surgun-Acar, Y.; Zemheri-Navruz, F. Physiological, biochemical, and molecular responses of wheat seedlings to salinity and plant-derived smoke. S. Afr. J. Bot. 2021, 139, 148-157. [CrossRef] 